\title{
EFFECTS OF CARBONATED RECYCLED CONCRETE AGGREGATES ON THE MECHANICAL PROPERTIES OF CONCRETE AND THE MICRO-PROPERTIES OF THE INTERFACIAL TRANSITION ZONE
}

\author{
JUN WU*, "YAHONG DING*, PING XU*, MEIXIANG ZHANG*,**, MENG GUO*, SHUQI GUO* \\ *School of Civil Engineering, Henan Polytechnic University, Jiaozuo 454003, China \\ **School of Architectural Engineering, Xinyu University, Xinyu 338004, China \\ "E-mail: dingyahong@hpu.edu.cn
}

Submitted December 17, 2021; accepted January 19, 2022

\begin{abstract}
Keywords: Accelerated carbonation; Recycled aggregate concrete; Interfacial transition zone; Strengthening mechanism; Calcite; Monocarbonate

The purpose of this paper was to study the effects of carbonated recycled concrete aggregates (CRCA) on the mechanical properties of recycled aggregate concrete (RAC) and the micro-properties of the interfacial transition zone (ITZ), and to determine their strengthening mechanisms. Recycled concrete aggregate (RCA) soaked with saturated lime water was treated by accelerated carbonation under a pressure of $0.30 \mathrm{MPa}$ for $24 \mathrm{~h}$, under the replacement ratios of $0 \%, 30 \%, 70 \%$, $100 \%$. The mechanical property tests included 7-day and 28-day compressive, splitting tensile, and flexural strength tests. The micro-property tests included scanning electron microscope-energy dispersive spectrometer (SEM-EDS), X-ray diffraction (XRD), and Vickers micro-hardness (VMH). The results showed that the pores of the old mortar (OM) and ITZ-2 in the CRCA were filled with calcite, which improved the properties of the CRCA. Therefore, with the replacement ratio of the CRCA, the improvement degrees of the mechanical properties of the RAC gradually increased. Furthermore, compared to the other phases in the RAC, ITZ-3 had the lowest properties, but had the highest improvement degree. Besides, the strengthening mechanism of the micro-properties of ITZ-3 by the CRCA can be explained by the nucleation and chemical effect of the calcite and the micro-bleeding effect of the ITZ-3. Namely, the calcite on the surface of the CRCA provided nucleation sites for the calcium silicate hydrate $(C-S-H)$ and reacted with the aluminate in the ITZ-3 to form hemicarbonate (Hc) and monocarbonate $(\mathrm{Mc})$. In addition, a decrease in the water absorption of the CRCA alleviated the micro-bleeding effect of the ITZ-3.
\end{abstract}

\section{INTRODUCTION}

With the rapid development of urbanisation, a great deal of construction and demolition waste (C\&DW) is generated every year [1], and most of it is usually piled in the suburbs or landfills, which not only occupies plenty of land, but also causes serious environmental pollution. On the other hand, the construction industry consumes a large amount of concrete, while the natural aggregate (NA) is almost exhausted. Therefore, in order to alleviate the environmental pressure imposed by the increasing C\&DW and solve the problem of the depleting natural resources, recycled aggregate concrete (RAC) has attracted considerable attention, which is prepared by recycled concrete aggregate (RCA) derived from C\&DW either through partially or totally replacing NA [2].

However, RCA is less valuable than NA because of the attached old mortar $(\mathrm{OM})$ and interfacial transition zone (ITZ), showing a lower apparent density, a higher water absorption and crushing value [3, 4]. Moreover, because the compositional structure of RAC is more complex than natural aggregate concrete (NAC) [5], the workability, mechanical properties, and durability of RAC are inferior to NAC [6-8]. As shown in Figure 1, NAC is a three-phase heterogeneous composite, including NA, new mortar (NM), and ITZ-1. By contrast, RAC is a six-phase heterogeneous composite, including NA, OM, NM, ITZ-1, ITZ-2, and ITZ-3. As a result, with the same mix proportion, the effective water-binder ratio of NM in RAC will be decreased due to the higher water absorption of the RCA, thus making the workability of RAC worse than that of NAC [9]. Furthermore, RCA with a higher water absorption will render a serious micro-bleeding effect in the ITZ-3, which will widen the ITZ-3 and reduce its Vickers micro-hardness (VMH) $[10,11]$. In fact, ITZ is the weakest phase in RAC, and it plays a crucial role in affecting the mechanical properties and durability of RAC $[12,13]$.

Consequently, it is necessary to improve the properties of RCA in order to promote its application in the engineering field. As an environmentally friendly $\mathrm{CO}_{2}$ sequestration technology, accelerated carbonation is considered to be an effective and feasible treatment method for the property improvement of RCA. Nowadays, 


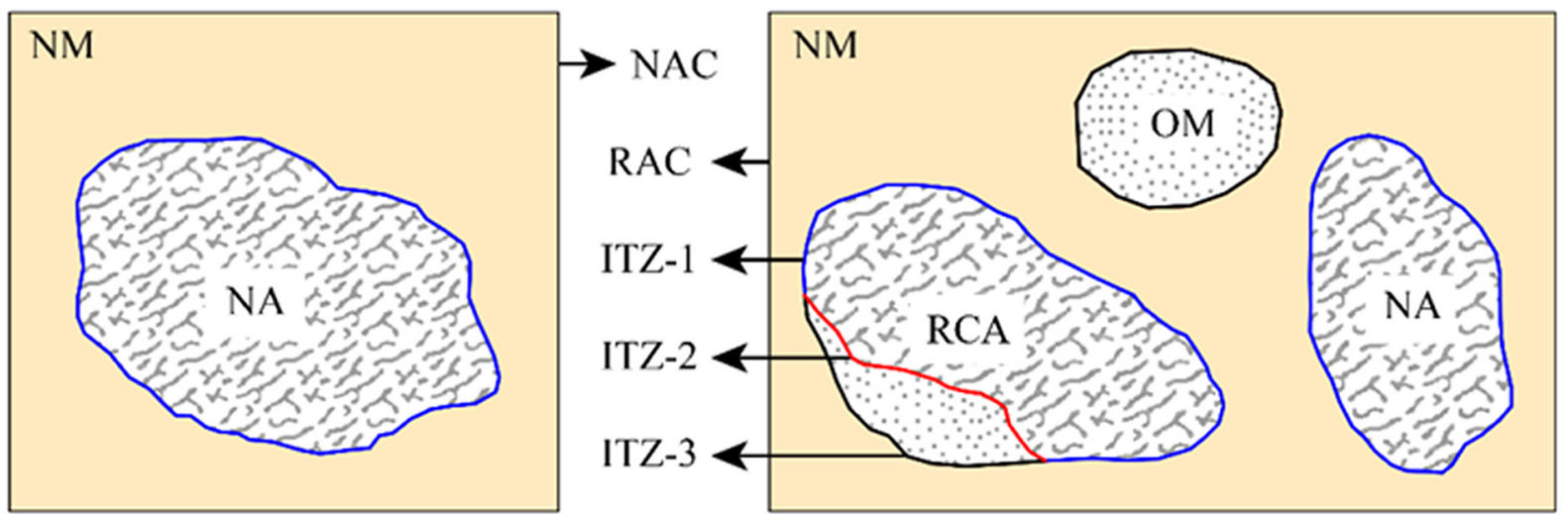

Figure 1. The compositional structures of NAC and RAC.

accelerated carbonation methods for the improvement of the RCA properties can be classified into four categories, including standard carbonation, pressurised carbonation, flow-through carbonation and water- $\mathrm{CO}_{2}$ carbonation [14], among which pressurised carbonation is widely used. For instance, Kou [15] found that after accelerated carbonation under a pressure of $0.01 \mathrm{MPa}$, the water absorption of carbonated recycled concrete aggregate (CRCA) decreases, and the density and $10 \%$ fine value of CRCA increase. Moreover, the mechanical properties and durability of RAC prepared by CRCA (CRAC) are improved. Xuan [16] utilised accelerated carbonation under a pressure of $0.01 \mathrm{MPa}$ and $0.50 \mathrm{MPa}$ to treat RCA with different ages, and found that the properties of the new RCA and the resulting RAC are more obviously improved than those of the old RCA and the resulting RAC. Li [17] adopted accelerated carbonation under a pressure of $0.01 \mathrm{MPa}$ to treat modelled RCA, and found that the VMH of the OM and ITZ-2 increase. Furthermore, the compressive strength and modulus of the modelled RAC increase, and the improvement degree becomes more obvious when the water-binder ratio becomes higher. Zhan [18] adopted accelerated carbonation under a pressure of $0.10 \mathrm{MPa}$ to treat modelled RCA, and found that a large quantity of calcite is formed on the surface of CRCA. Besides, calcite provides nucleation sites for $\mathrm{C}-\mathrm{S}-\mathrm{H}$ and also reacts with the aluminate in ITZ-3 to form monocarbonate $(\mathrm{Mc})$. Therefore, the porosity of ITZ-3 decreases and the VMH of ITZ-3 increases.

In addition, in order to enhance the carbonation effect, RCA can be soaked in a $\mathrm{Ca}^{2+}$ rich solution to obtain a pre-treatment. For example, Pan [19] reported that the properties of recycled fine aggregate can be further improved by soaking it in a calcium hydroxide solution before accelerated carbonation, and the fluidity and compressive strength of the mortar prepared by carbonated recycled fine aggregate can also be further improved. Zhan [20] found that after a mortar experienced 3-cycles of a limewater- $\mathrm{CO}_{2}$ treatment, its density increased by $5.70 \%$, while its water absorption decreased by over $50.00 \%$. Moreover, its compressive and flexural strength increased by $22.80 \%$ and $42.40 \%$, respectively. Furthermore, the total porosity reduced by about $33.00 \%$, and the densified micro-structure led to a higher VMH. Fang [21] also found the carbonation effect of flow-through carbonation can be further improved by soaking the RCA in $\mathrm{Ca}^{2+}$ rich wastewater, and the compressive strength and chloride penetration of RAC were improved, which is attributed to the decreased porosity and the increased VMH of OM.

The above-mentioned research showed that CRCA can improve the properties of RAC. However, in terms of introducing $\mathrm{Ca}^{2+}$ into the RCA to enhance the carbonation effect of pressurised carbonation, recycled fine aggregate and mortar are always adopted as the research objects in the existing literature, while there is still a lack of research on RCA and RAC. Therefore, the purpose of this paper was to study the effects of CRCA on the mechanical properties of RAC and the micro-properties of ITZ, and to determine their strengthening mechanisms. RCA soaked with saturated lime water was treated by accelerated carbonation under a pressure of $0.30 \mathrm{MPa}$ for $24 \mathrm{~h}$. The replacement ratios of CRCA were $0 \%, 30 \%$, $70 \%, 100 \%$. The mechanical property tests of the RAC included compressive strength, splitting tensile strength, and flexural strength at the ages of 7 days and 28 days. The micro-property tests of ITZ included scanning electron microscope-energy dispersive spectrometer (SEM-EDS), X-ray diffraction (XRD), and VMH.

\section{EXPERIMENTAL}

\section{Materials}

\section{Cement and mixing water}

The ordinary Portland cement $(\mathrm{P} \bullet \mathrm{O} 42.5)$ used in this study was produced by Jiaozuo Qianye Cement Co., Ltd., and its chemical composition is shown in Table 1. Moreover, its density was $3.14 \mathrm{~g} \cdot \mathrm{cm}^{-3}$, and its specific surface area was $3550 \mathrm{~cm}^{2} \cdot \mathrm{g}^{-1}$, all the parameters were provided by the cement manufacturer. Besides, tap water was used as the mixing water. 
Effects of carbonated recycled concrete aggregates on the mechanical properties of concrete and the micro-properties of...

Table 1. The chemical composition of the cement

\begin{tabular}{lccccccccc}
\hline Composition & $\mathrm{CaO}$ & $\mathrm{SiO}_{2}$ & $\mathrm{Al}_{2} \mathrm{O}_{3}$ & $\mathrm{Fe}_{2} \mathrm{O}_{3}$ & $\mathrm{MgO}$ & $\mathrm{K}_{2} \mathrm{O}$ & $\mathrm{Na}_{2} \mathrm{O}$ & $\mathrm{SO}_{3}$ & Loss on ignition \\
\hline Content $(\%)$ & 65.67 & 22.35 & 5.42 & 3.56 & 1.54 & 0.46 & 0.68 & 0.65 & 2.53 \\
\hline
\end{tabular}

\section{Natural river sand}

Natural river sand was used as the fine aggregate. According to GB/T 14684-2011 Sand for Construction, the physical and mechanical properties of the natural river sand were obtained, as shown in Table 2. Moreover, the particle size distribution curve of the natural river sand is shown in Figure 2, and its fineness modulus was 2.84 , belonging to medium sand in zone II.

\section{$N A$ and $R C A$}

The NA was purchased from the local construction material market, the NA had a particle size of $5-10 \mathrm{~mm}$ and $10-20 \mathrm{~mm}$, which are denoted as NA-1 and NA-2, respectively. The RCA was derived from the abandoned concrete beams in the laboratory whose design strength grade was $\mathrm{C} 30$ and age was 6 months. The concrete beams were broken manually and then sieved into RCA-1 (5 $10 \mathrm{~mm}$ ) and RCA-2 (10 - $20 \mathrm{~mm})$. According to GB/T 14685-2011 Pebble and Crushed Stone for Construction, the physical and mechanical properties of the NA and RCA were obtained, as shown in Table 2. The particle size distribution curves of the NA and RCA are shown in Figure 3, with a mass ratio of 1:2 for NA-1:NA-2 and RCA-1:RCA-2. The NA and RCA used in this study are shown in Figure 4.

As shown in Figure 5, the volume of the accelerated carbonation device was about $50 \mathrm{~L}$, and the volume fraction of the industrial liquid $\mathrm{CO}_{2}$ was over $99 \%$. Before the accelerated carbonation, the RCA was soaked in saturated lime water for $24 \mathrm{~h}$, and then placed into a constant temperature and humidity box (temperature $20{ }^{\circ} \mathrm{C}$, humidity $70 \%$ ) for $24 \mathrm{~h}$. After the RCA was put it into the device, the air in the device was pumped out by a vacuum pump until the pressure reached -0.06 $\mathrm{MPa}$. In the process of the accelerated carbonation, the temperature and humidity in the device were not controlled, while the carbonation pressure was kept at $0.30 \mathrm{MPa}$ and the carbonation time was $24 \mathrm{~h}$. After the accelerated carbonation, according to GB/T 14685-2011 Pebble and Crushed Stone for Construction, the physical and mechanical properties of the CRCA were obtained, as shown in Table 2.

Table 2. The physical and mechanical properties of the aggregate.

\begin{tabular}{ccccc}
\hline $\begin{array}{c}\text { Aggregate } \\
\text { type }\end{array}$ & $\begin{array}{c}\text { Particle size } \\
(\mathrm{mm})\end{array}$ & $\begin{array}{c}\text { Apparent density } \\
\left(\mathrm{kg} \cdot \mathrm{m}^{-3}\right)\end{array}$ & $\begin{array}{c}\text { Water absorption } \\
(\%)\end{array}$ & $\begin{array}{c}\text { Crushing value } \\
(\%)\end{array}$ \\
\hline Sand & $0-4.75$ & 2629 & 0.70 & 25.35 \\
NA-1 & $5-10$ & 2703 & 0.55 & 13.41 \\
RCA-1 & $5-10$ & 2690 & 5.85 & 23.87 \\
CRCA-1 & $5-10$ & 2697 & 4.74 & 22.81 \\
NA-2 & $10-20$ & 2723 & 0.60 & 11.11 \\
RCA-2 & $10-20$ & 2697 & 3.74 & 16.11 \\
CRCA-2 & $10-20$ & 2707 & 3.34 & 14.93 \\
\hline
\end{tabular}

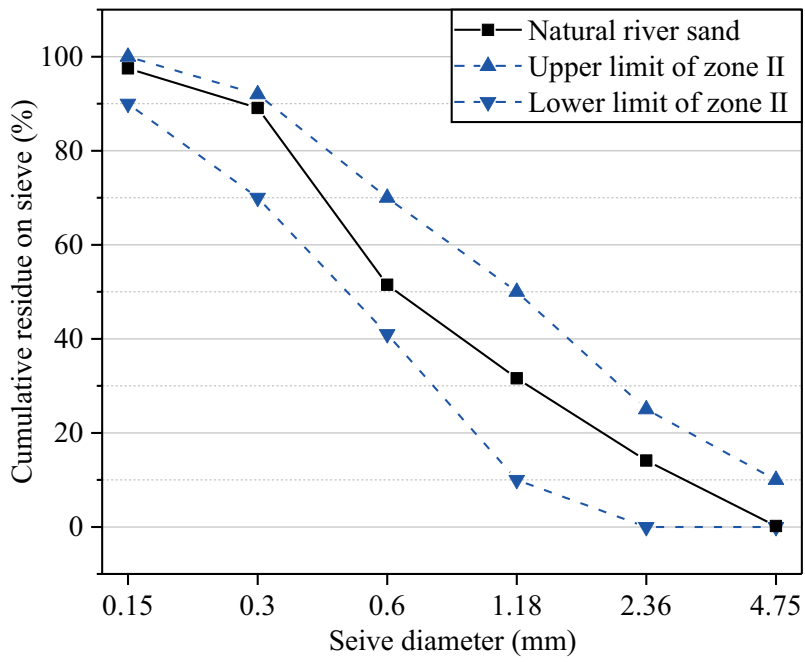

Figure 2. The particle size distribution curve of the natural river sand.

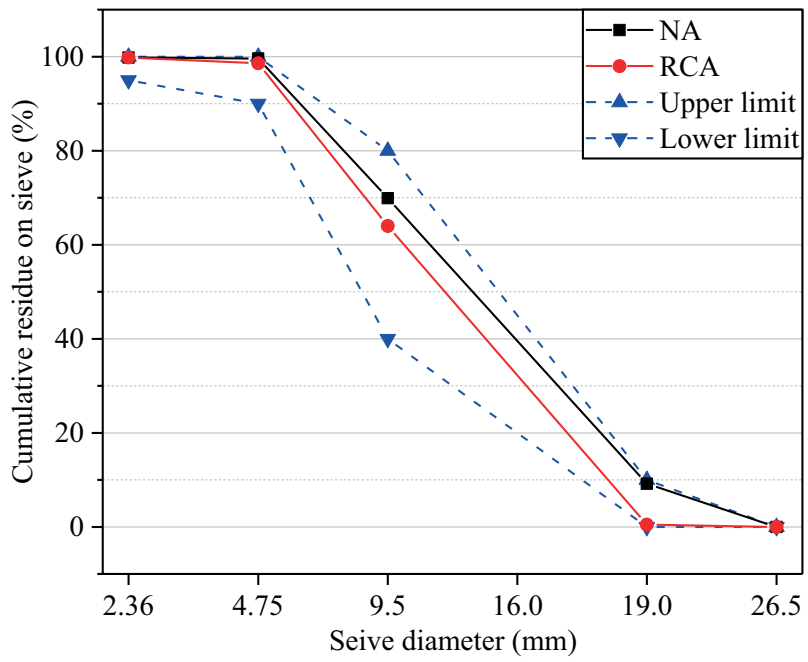

Figure 3. The particle size distribution curves of the NA and RCA. 


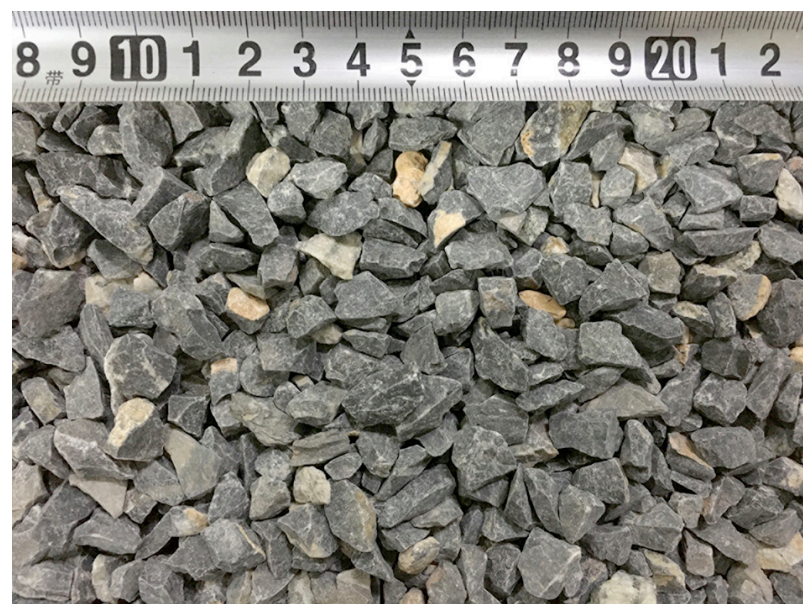

a)

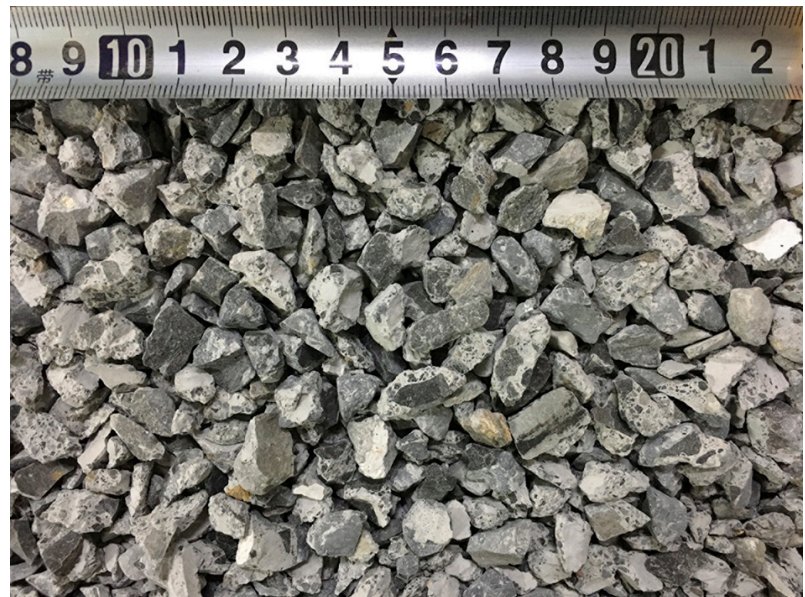

c)

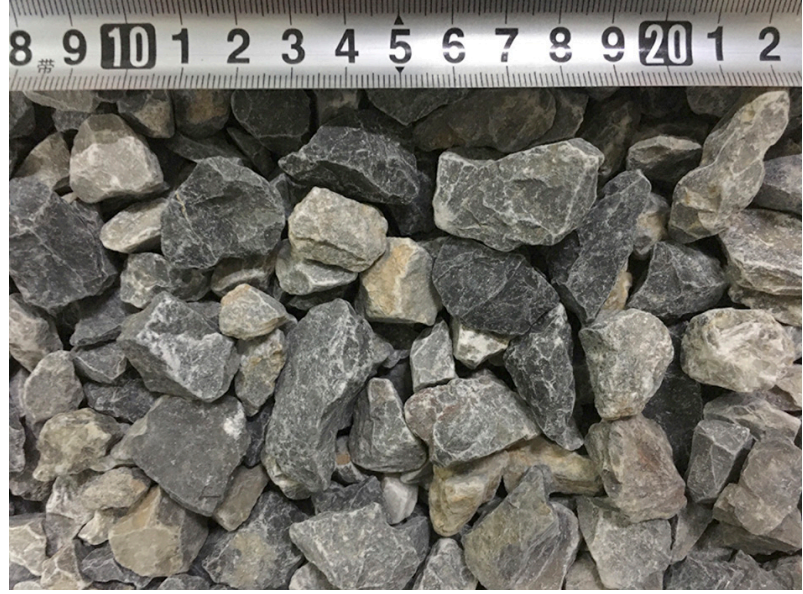

b)

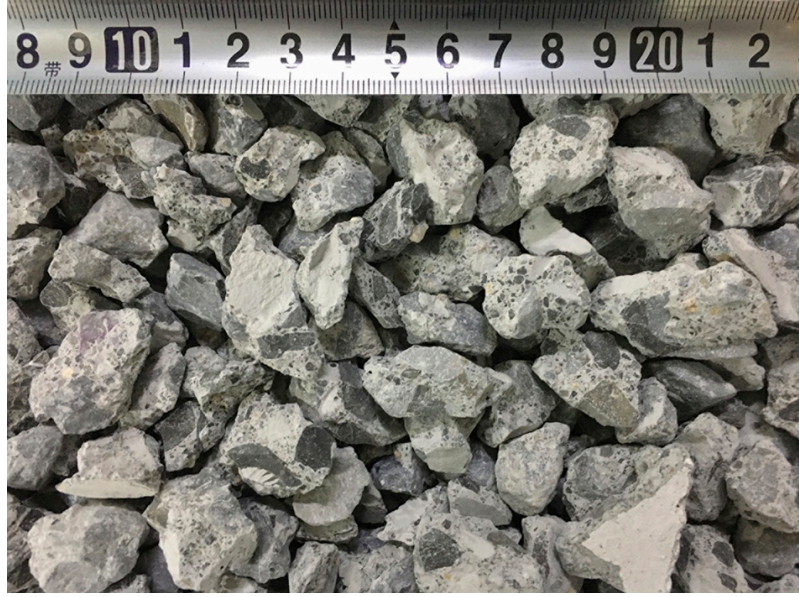

d)

Figure 4. NA and RCA: a) NA-1, 5-10 mm; b) NA-2, 10-20 mm; c) RCA-1, 5-10 mm; d) RCA-2, 10-20 mm.
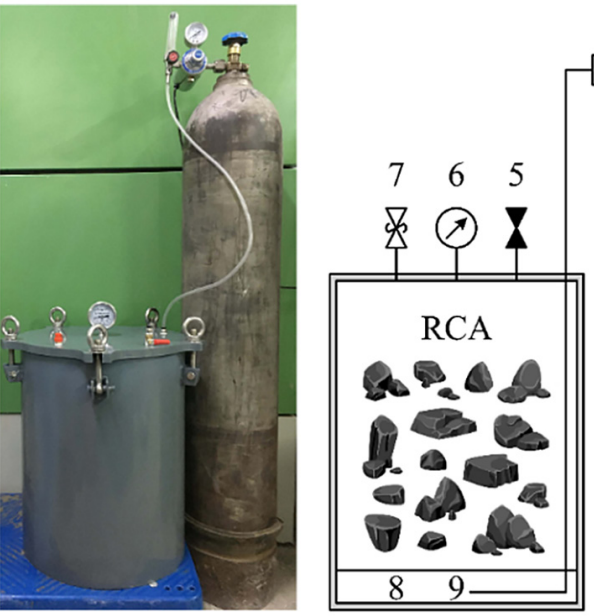

\section{$4 \quad 3>2$}
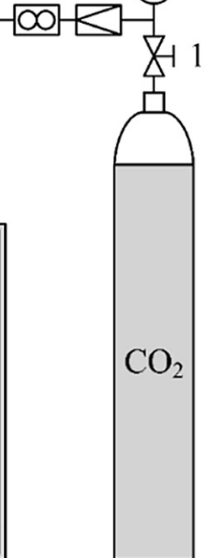

1-Rotary valve 2-Pressure gauge 3 -Pressure reducing valve 4-Flow meter 5-Exhaust valve 6-Pressure gauge 7 -Safety valve 8 -Perforated plate $9-\mathrm{CO}_{2}$ outlet

Figure 5. Accelerated carbonation device.
Mix proportions

The mix proportions of the RAC were designed according to JGJ 55-2011 Specification for Mix Proportion Design of Ordinary Concrete and JGJ/T 443-2018 Technical Standard for Recycled Concrete Structures. The design strength grade was $\mathrm{C} 40$ and the water-binder ratio was 0.49 .

The mix proportions of the RAC are shown in Table 3 . Before the mixing process, the NA, RCA, and CRCA were soaked in water for $24 \mathrm{~h}$, then the saturated surface was wiped to a dry state. The mass ratio of 1:2 was used for NA-1:NA-2, RCA-1:RCA-2, and CRCA1 :CRCA-2 in this study.

\section{Specimen preparation and curing}

The RAC specimens were prepared and cured according to GB/T 50081-2019 Standard for Test Methods of Concrete Physical and Mechanical Properties. Firstly, the cement and sand were put into the forced concrete mixer and mixed for $1 \mathrm{~min}$. Afterwards, water was put into the mixer and mixed for 1 min. Finally, the RCA 
Table 3. The mix proportions of the RAC.

\begin{tabular}{ccccccccc}
\hline $\begin{array}{c}\text { Specimen } \\
\text { type }\end{array}$ & $\begin{array}{c}\text { Replacement } \\
\text { ratio }(\%)\end{array}$ & $\begin{array}{c}\mathrm{NA} \\
\left(\mathrm{kg} \cdot \mathrm{m}^{-3}\right)\end{array}$ & $\begin{array}{c}\mathrm{RCA} \\
\left(\mathrm{kg} \cdot \mathrm{m}^{-3}\right)\end{array}$ & $\begin{array}{c}\text { CRCA } \\
\left(\mathrm{kg} \cdot \mathrm{m}^{-3}\right)\end{array}$ & $\begin{array}{c}\text { Sand } \\
\left(\mathrm{kg} \cdot \mathrm{m}^{-3}\right)\end{array}$ & $\begin{array}{c}\text { Cement } \\
\left(\mathrm{kg} \cdot \mathrm{m}^{-3}\right)\end{array}$ & $\begin{array}{c}\text { Water } \\
\left(\mathrm{kg} \cdot \mathrm{m}^{-3}\right)\end{array}$ & $\begin{array}{c}\text { Slump } \\
(\mathrm{mm})\end{array}$ \\
\hline NAC & 0 & 1134 & 0 & 0 & 611 & 440 & 215 & 105 \\
RAC-1 & 30 & 794 & 340 & 0 & 611 & 440 & 215 & 100 \\
RAC-2 & 70 & 340 & 794 & 0 & 611 & 440 & 215 & 95 \\
RAC-3 & 100 & 0 & 1134 & 0 & 611 & 440 & 215 & 90 \\
CRAC-1 & 30 & 794 & 0 & 340 & 611 & 440 & 215 & 100 \\
CRAC-2 & 70 & 340 & 0 & 794 & 611 & 440 & 215 & 90 \\
CRAC-3 & 100 & 0 & 0 & 1134 & 611 & 440 & 215 & 80 \\
\hline
\end{tabular}

was put into the mixer and mixed for 2 min. After the mixing process was finished, the fresh RAC was placed into a mould, and it was densified by a vibration table for $20 \mathrm{~s}$. After that, the surfaces of the specimens were smoothed and immediately covered with plastic film. After standing in the laboratory for $24 \mathrm{~h}$, the specimens were numbered and demoulded. Finally, the specimens were placed into a standard curing box (temperature $20{ }^{\circ} \mathrm{C}$, humidity $95 \%$ ) and cured to 7 days and 28 days.

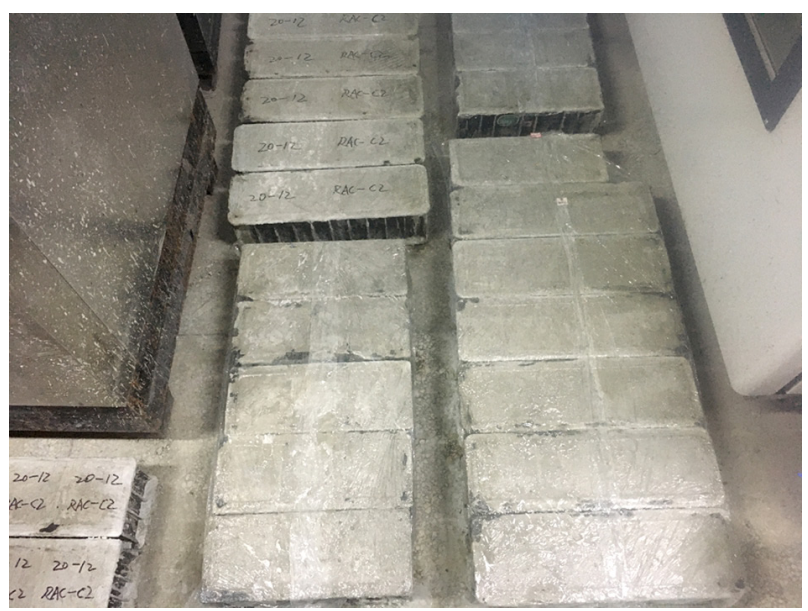

Figure 6. The RAC specimens.

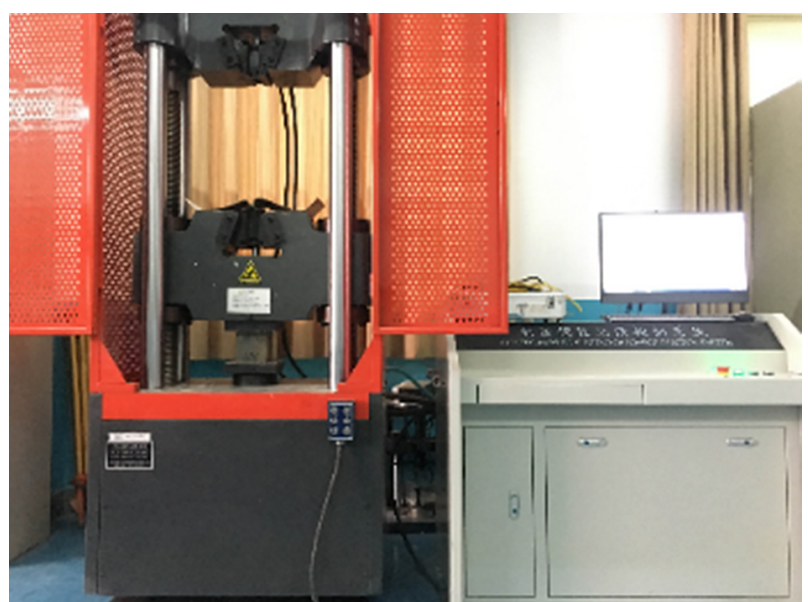

Figure 7. The WAW-600 electro-hydraulic servo universal testing machine.
The compressive strength and splitting tensile strength were tested on cubic specimens, whose sizes were $100 \times 100 \times 100 \mathrm{~mm}$, while the flexural strength was tested with prismatic specimens, whose sizes were $100 \times 100 \times 400 \mathrm{~mm}$. Each group of tests had three specimens. The RAC specimens are shown in Figure 6.

\section{RAC mechanical property tests}

According to GB/T 50081-2019 Standard for Test Methods of Concrete Physical and Mechanical Properties, the mechanical properties of the RAC specimens were tested by a WAW-600 electro-hydraulic servo universal testing machine as shown in Figure 7 . The loading rate of the compressive strength tests was $0.50 \mathrm{MPa} \cdot \mathrm{s}^{-1}$, and that of the splitting tensile strength tests and flexural strength tests was $0.05 \mathrm{MPa} \cdot \mathrm{s}^{-1}$. Each group of tests had three specimens, and their arithmetic mean was used as the final test result.

\section{ITZ micro-property tests}

\section{$S E M-E D S$}

RCA-1 and CRCA-1 were selected to study the changes in the ITZ-2 and OM before and after the accelerated carbonation. Besides, in order to study the changes in the hydration products in ITZ-1 and ITZ-3, the RAC-2 and CRAC-2 fragments after the 28-day compressive strength tests were selected, then the NA and NM were separated along with the ITZ-1, while the OM and NM were separated along with the ITZ-3.

Before the SEM-EDS tests, all the specimens were dried in a forced convection drying oven at $65{ }^{\circ} \mathrm{C}$ for $24 \mathrm{~h}$, and then sprayed with gold. The micro-morphology of the OM and ITZ was observed by the field emission SEM (Merlin Compact, accelerated voltage $15 \mathrm{kV}$ ), and the elemental analyses of the mineral crystals were carried out by EDS.

\section{$X R D$}

The specimen preparation for the XRD analysis is shown in Figure 8. Two cubic NAC specimens were prepared using the mix proportions in Table 3. After 


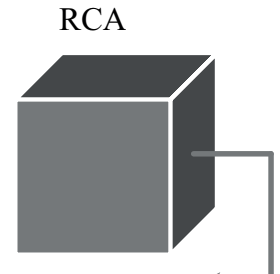

Specimen 1

Specimen 2

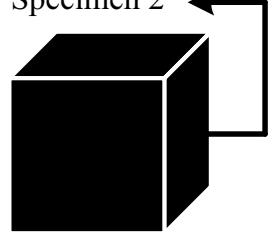

CRCA

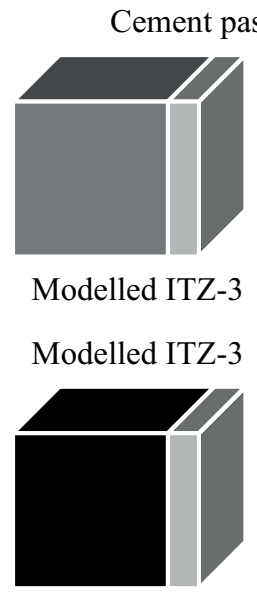

Cement paste
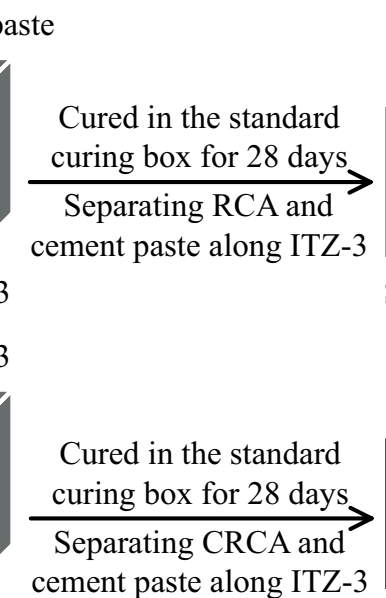
cement paste along ITZ-3

Specimens were obtained by scraping powder from the surfaces of RCA, CRCA, and cement paste

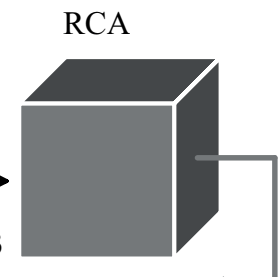

Specimen 3

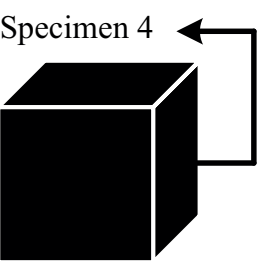

CRCA

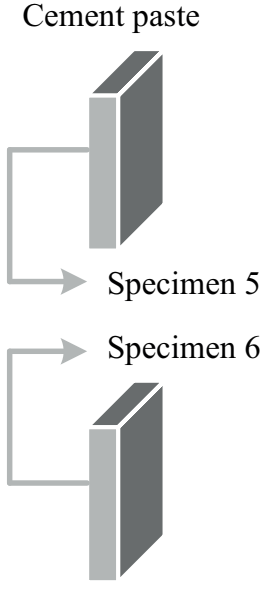

Cement paste
RCA, CRCA

$\mathrm{a}=\mathrm{b}=\mathrm{c}=100 \mathrm{~mm}$

Figure 8. The specimen preparation for the XRD analysis.

curing in the standard curing box (temperature $20{ }^{\circ} \mathrm{C}$, humidity $95 \%$ ) for 28 days, one whole cubic specimen was treated by the accelerated carbonation in Section 2.1.4 to obtain the CRCA. Afterwards, specimens 1 and 2 were obtained by scraping powder from the surfaces of the RCA and CRCA, respectively. In addition, cement paste with a water-cement ratio of 0.4 was poured onto the surfaces of the RCA and CRCA to form the modelled ITZ-3, and then they were cured in the standard curing box (temperature $20{ }^{\circ} \mathrm{C}$, humidity $95 \%$ ) for 28 days. Finally, specimens 3 and 5 were obtained by scraping powder from the contact surfaces at the ITZ of RCAcement paste, while specimens 4 and 6 were taken from the contact surfaces at the ITZ of CRCA-cement paste.

Before the XRD tests, all the specimens were dried in the forced convection drying oven at $65^{\circ} \mathrm{C}$ for $24 \mathrm{~h}$, then the specimens were sieved through a 360-mesh sieve. An X-ray diffractometer (Smart Lab 9 kw, $40 \mathrm{kV}$, $200 \mathrm{~mA}, \mathrm{Cu} \mathrm{K \alpha}$ ) was utilised to conduct the tests, with a scanning range of $5-70^{\circ}$, a scanning step size of $0.02^{\circ}$, and a scanning speed of $10^{\circ} \cdot \mathrm{min}^{-1}$.

\section{$V M H$}

The RCA-1 and the RAC-2 and CRAC-2 fragments after the 28-day compressive strength tests were dried in the forced convection drying oven at $65{ }^{\circ} \mathrm{C}$ for $24 \mathrm{~h}$, then the specimens containing ITZ-1, TZ-2, and ITZ-3 were selected. Next, the surfaces of the specimens were polished by 220-mesh sandpaper. Afterward, the specimens were placed into cylindrical moulds with a diameter of $25 \mathrm{~mm}$, then epoxy resin was poured in and cured for $24 \mathrm{~h}$. After the specimens were demoulded, their surfaces were successively polished by $220-, 800-$, and 2000-mesh sandpaper, and anhydrous ethanol was used to clean them. Finally, the VMH specimens were obtained, as shown in Figure 9. In addition, in order to obtain the VMH of the OM and ITZ-2 in the CRCA, the VMH specimens containing RCA-1 were treated by the accelerated carbonation process in Section 2.1.4.

The specimens were tested in a VMH tester (HMAS-C1000SZ), which was produced by Shanghai MicroCre Light-Mach Tech Co., Ltd. The test load was $10 \mathrm{~g}$, and the loading time was $10 \mathrm{~s}$. The test point layout of the VMH is shown in Figure 10. Two rows of parallel test points were staggered, with a spacing of $20 \mu \mathrm{m}$ and a row spacing of $30 \mu \mathrm{m}$. Each group of tests had two specimens, and their arithmetic mean was used as the final test result.

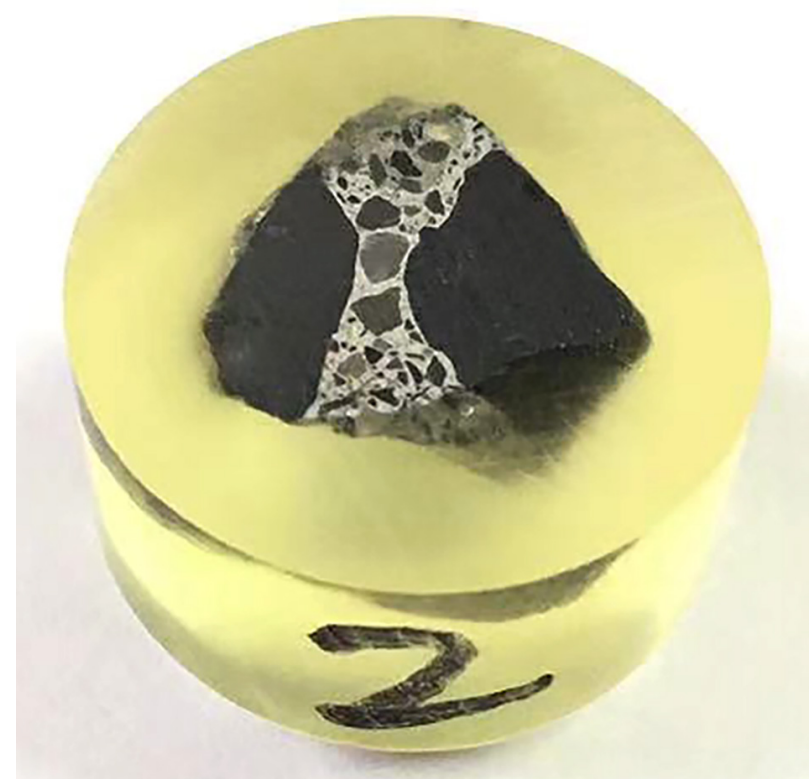

Figure 9. The VMH specimen. 


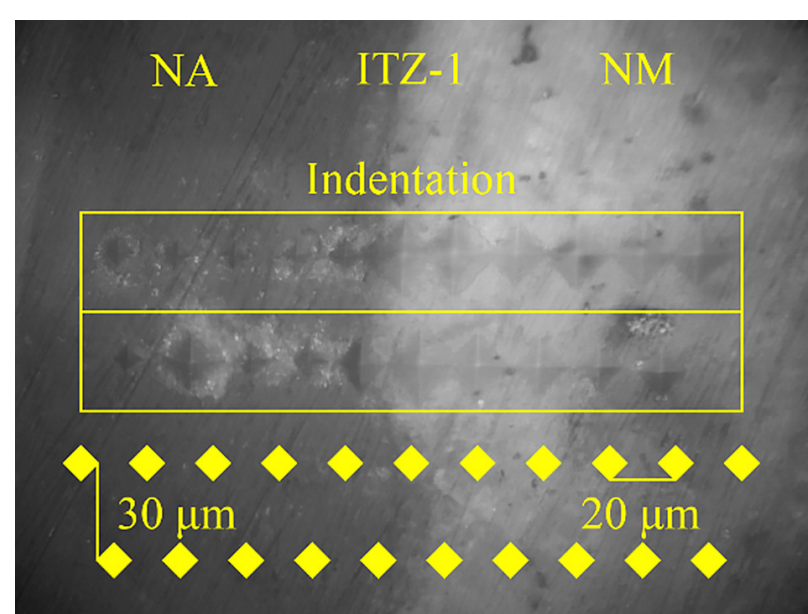

Figure 10. The test point layout of the VMH.

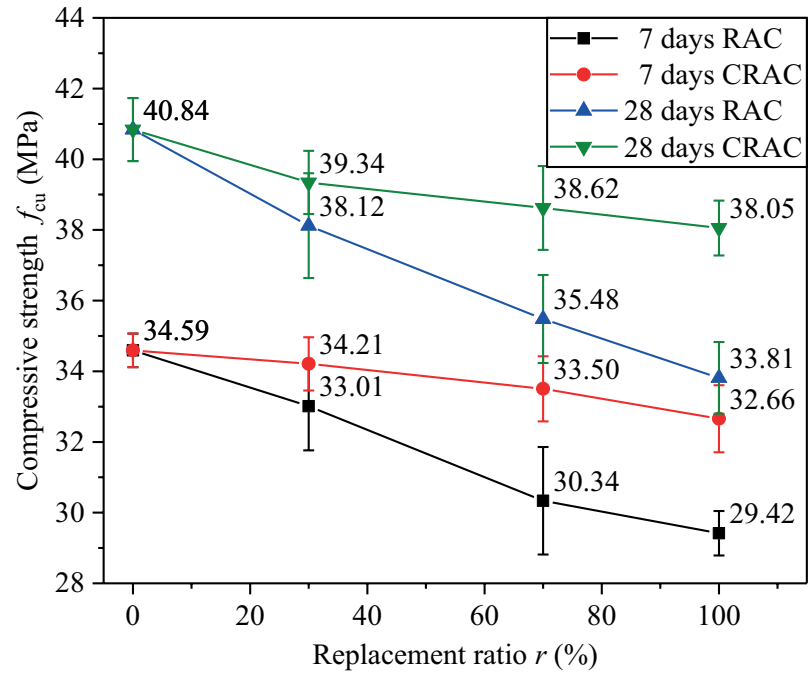

a)

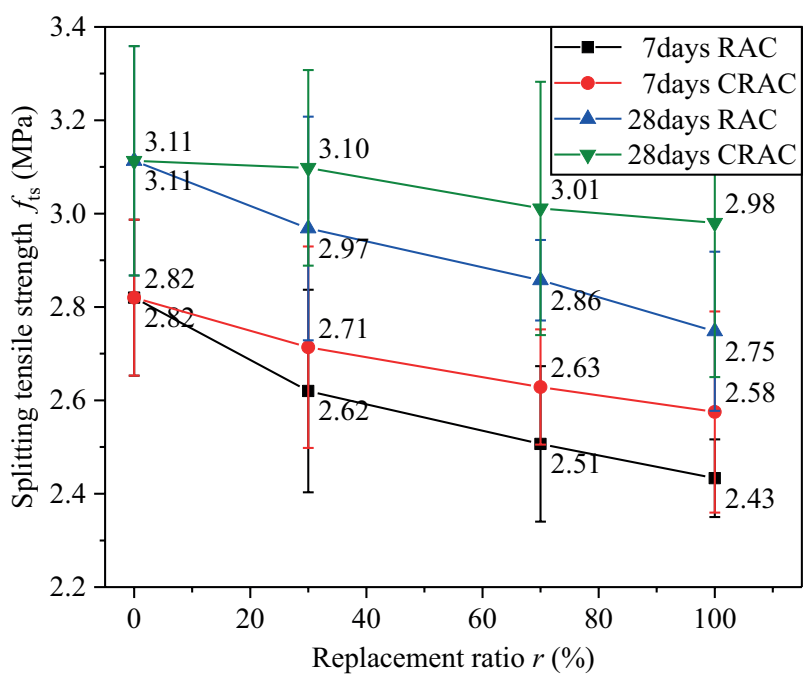

c)

\section{RESULTS}

Mechanical property tests of the RAC

Mechanical properties of the $R A C$

The mechanical properties of the RAC are shown in Figure 11. It can be seen from Figures 11a,c,e that the mechanical properties of the RAC and CRAC at the ages of 7 and 28 days gradually decreased with the replacement ratios of the RCA and CRCA, but those of the CRAC were always higher than those of the RAC. Moreover, as can be seen from Figures 11b,d,f, the improvement degrees in the mechanical properties between the RAC and CRAC gradually increased with the replacement ratios of the RCA and CRCA.

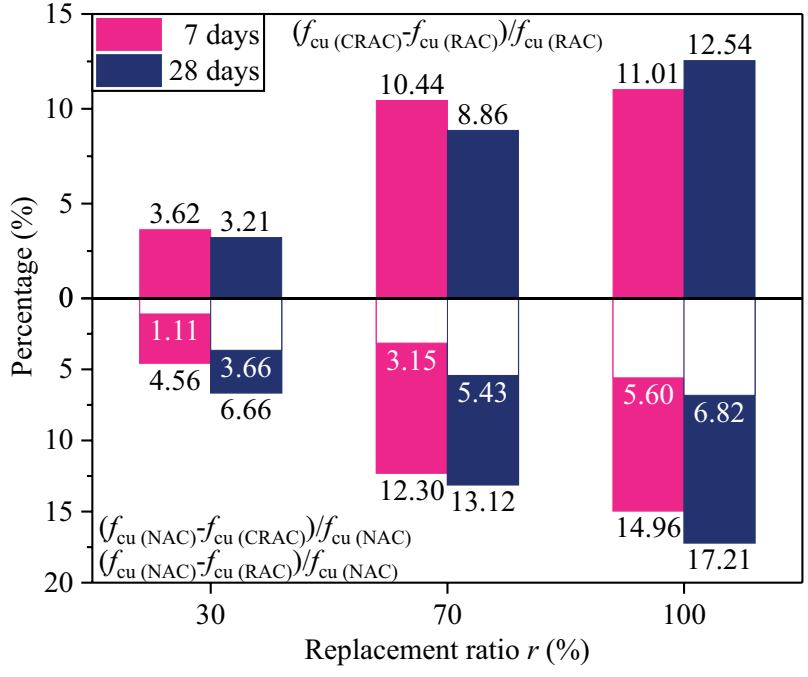

b)

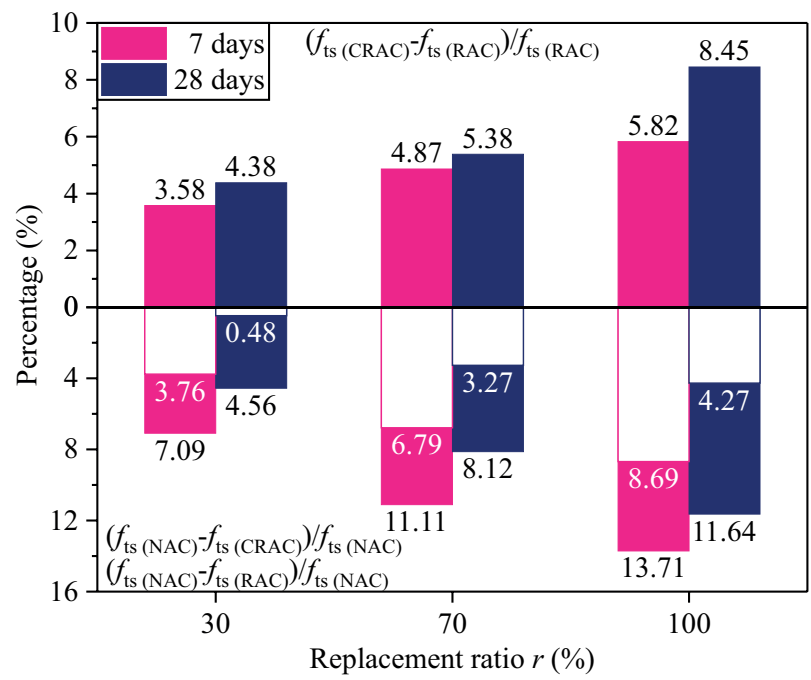

d)

Figure 11. The mechanical properties of the RAC: a) compressive strength; b) percentage change in the compressive strength; c) splitting tensile strength; d) Percentage change in the splitting tensile strength. (Continue on next page) 


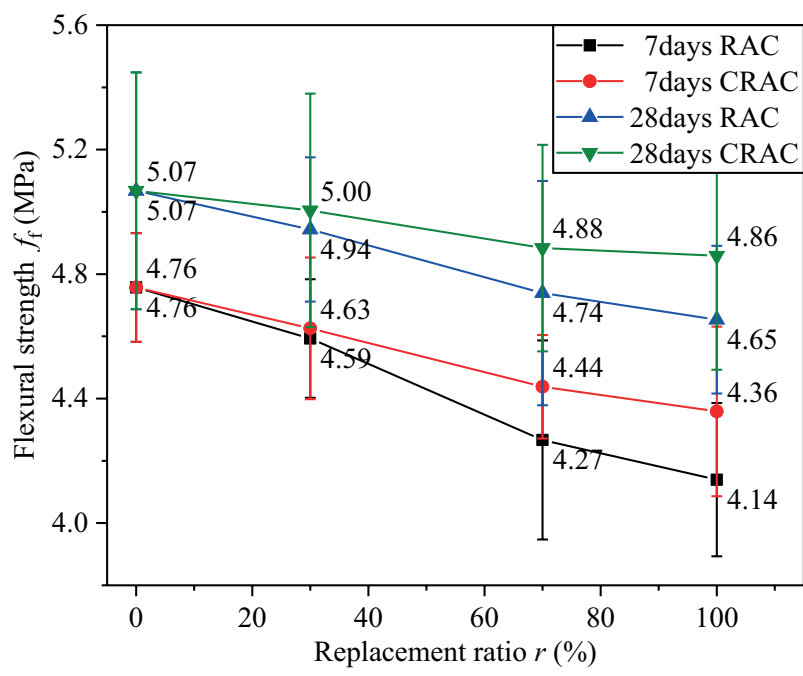

e)

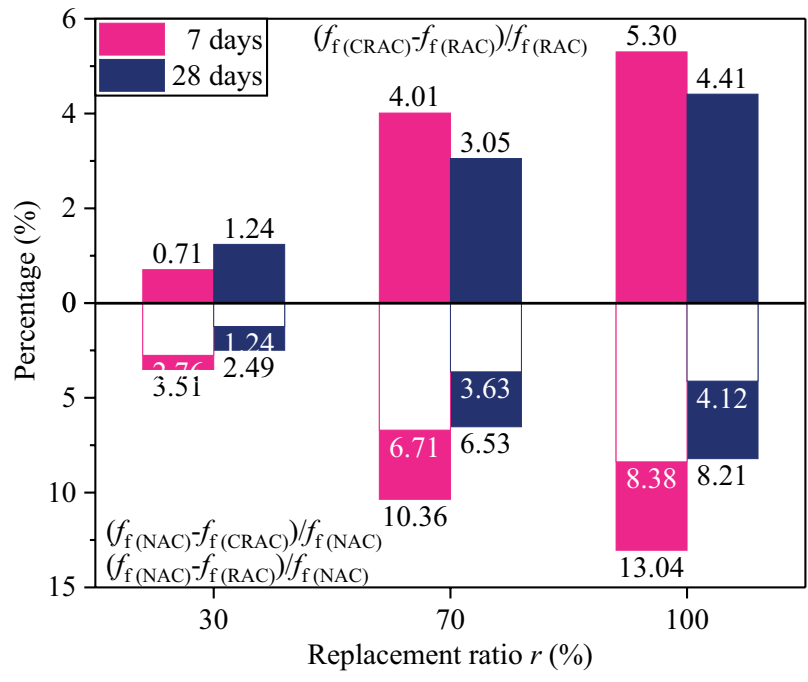

f)

Figure 11. The mechanical properties of the RAC: e) flexural strength; f) percentage change in the flexural strength.

\section{Relationships between the mechanical properties of the $R A C$}

The relationship between the splitting tensile strength and the compressive strength is shown in Figure 12. According to equation $f_{\mathrm{ts}}=0.19 f_{\mathrm{cu}}^{0.75}$ in $\mathrm{GB}$ 50010-2010 Code for Design of Concrete Structures, and equation $f_{\mathrm{ts}}=0.30 f_{\mathrm{cu}}^{0.67}$ in fib Model Code for Concrete Structures 2010, equation $f_{\mathrm{ts}}=0.17 f_{\mathrm{cu}}{ }^{0.78}$ with a correlation coefficient $R^{2}$ of 0.97 was obtained through fitting the test data. It can be seen that the relationship between the mechanical properties of RAC conformed to that of NAC, and the agreement between $f_{\mathrm{ts}}=0.19 f_{\mathrm{cu}}{ }^{0.75}$ and the test data was higher than $f_{\mathrm{ts}}=0.30 f_{\mathrm{cu}}{ }^{0.67}$.

The relationship between the flexural strength and compressive strength is shown in Figure 13. According to equation $f_{\mathrm{f}}=0.75 f_{\mathrm{cu}}{ }^{0.50}$ in DG/T J08-2018 Technical
Code on the Application of Recycled Concrete, and equation $f_{\mathrm{f}}=0.50 f_{\mathrm{cu}}{ }^{0.67}$ in fib Model Code for Concrete Structures 2010, equation $f_{\mathrm{f}}=0.59 f_{\text {cu }}^{0.58}$ with a correlation coefficient $R^{2}$ of 0.93 was obtained through fitting the test data. It can be seen that the relationship between the mechanical properties of RAC conformed to that of $\mathrm{NAC}$, and the agreement between $f_{\mathrm{f}}=0.75 f_{\mathrm{cu}}{ }^{0.50}$ and the test data was higher than $f_{\mathrm{f}}=0.50 f_{\mathrm{cu}}^{0.67}$.

The relationships between the mechanical properties and the ages of the RAC are shown in Figure 14. It can be seen that the aggregate replacement ratio had little effect on the relationships between the mechanical properties and the ages of the RAC. The ratios of the 7-day to 28-day compressive strength, splitting tensile strength, and flexural strength of the RAC were 0.85 - 0.87 , $0.87-0.91$, and $0.89-0.94$, respectively.

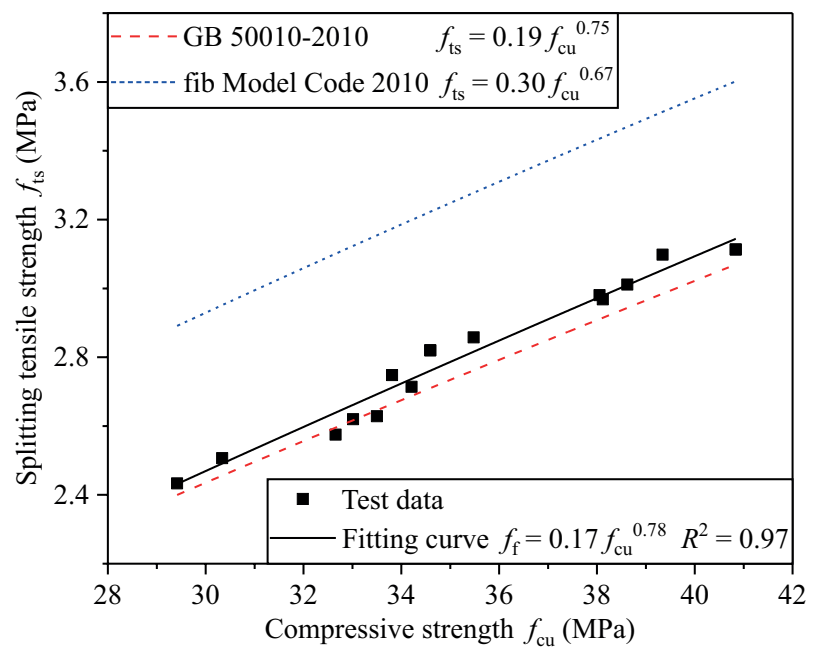

Figure 12. The relationship between the splitting tensile strength and the compressive strength.

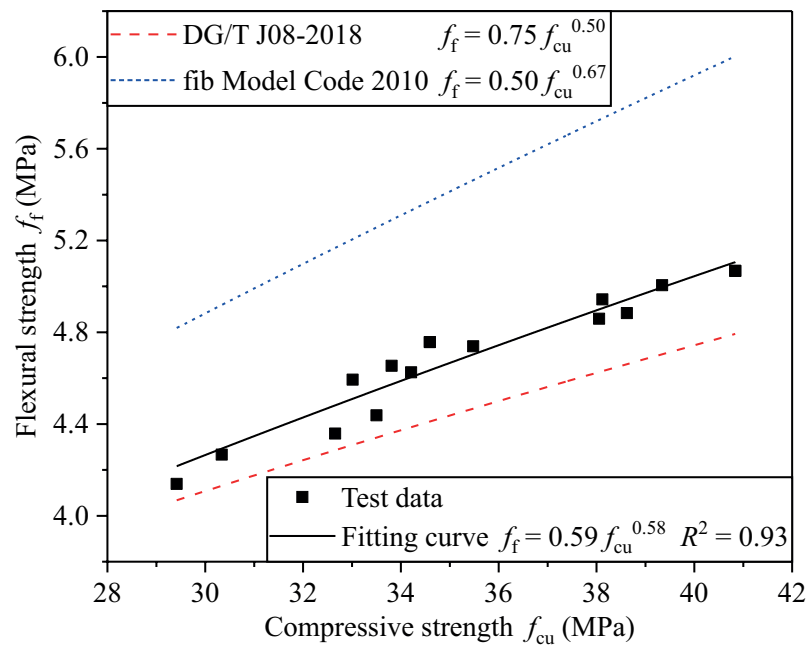

Figure 13. The relationship between the flexural strength and the compressive strength. 


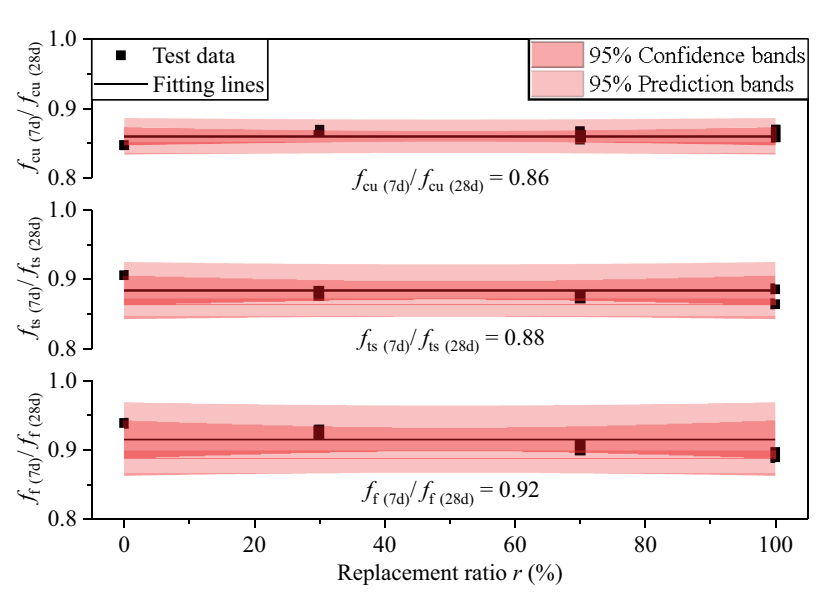

Figure 14. The relationships between the mechanical properties and the ages of the RAC.

\section{Micro-property tests of the ITZ}

\section{SEM-EDS}

The micro-morphology of the ITZ-2 and OM in RCA-1 and CRCA-1 is shown in Figure 15. As shown in Figures $15 \mathrm{a}$ and $15 \mathrm{~b}$, before the accelerated carbonation, the contact boundaries between ITZ-2 and NA in RCA-1 were clearly visible. By contrast, as shown in Figures $15 \mathrm{c}$ and $15 \mathrm{~d}$, after the accelerated carbonation, the contact boundaries between ITZ-2 and NA in CRCA-1 became blurred, because its surface was covered by a large amount of rhombohedral calcite. Similarly, as shown in Figures 15e and 15f, the surface of OM in CRCA-1 was also covered by a large amount of rhombohedral calcite, which filled its pores and voids. Therefore, as shown in Table 2, compared to the RCA, the properties

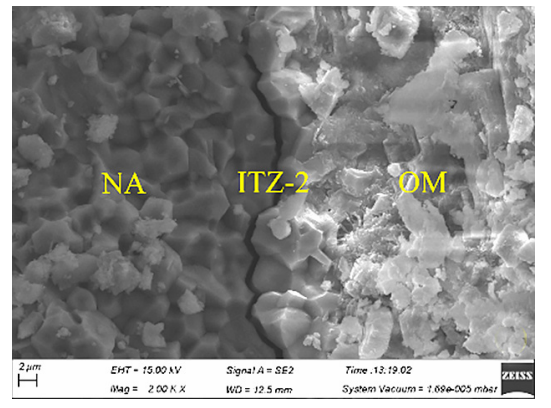

a)

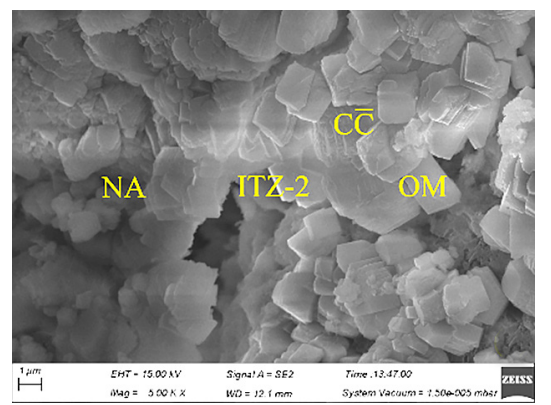

d)

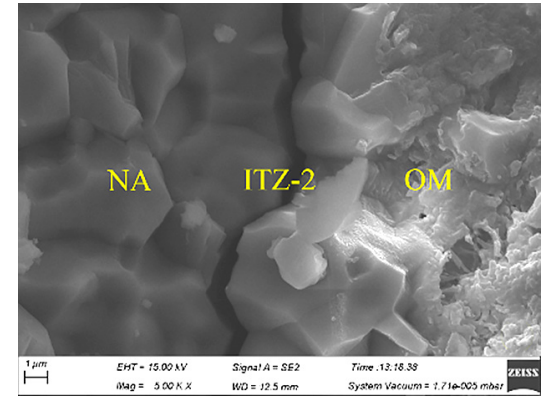

b)

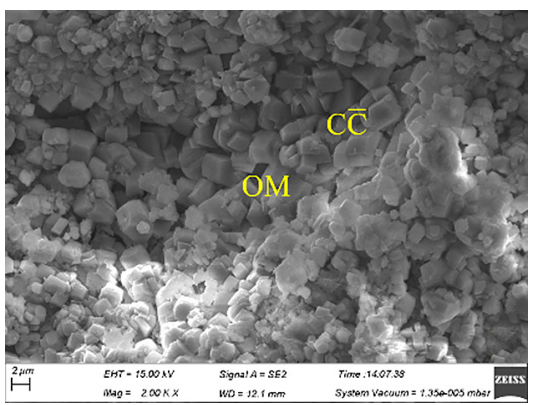

e)

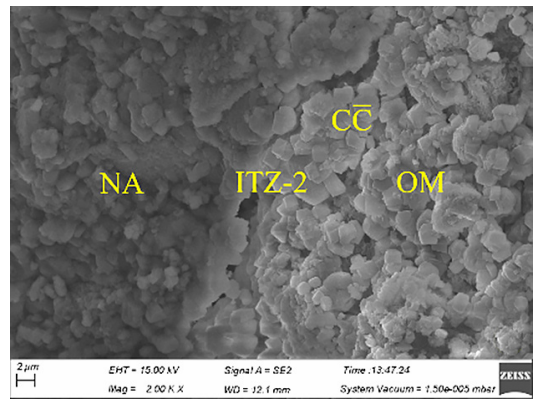

c)

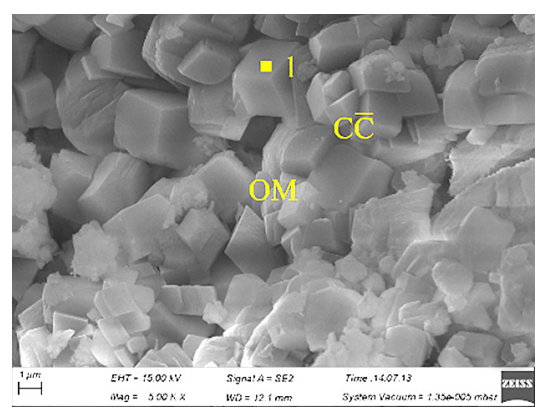

f)

Figure 15. The micro-morphology of ITZ-2 and OM in RCA-1 and CRCA-1: a) 2 kx, ITZ-2 in RCA-1; b) 5 kx, ITZ-2 in RCA-1; c) $2 \mathrm{kx}$, ITZ-2 in CRCA-1; d) $5 \mathrm{kx}$, ITZ-2 in CRCA-1; e) $2 \mathrm{kx}$, OM in CRCA-1; f) $5 \mathrm{kx}$, OM in CRCA-1 (CC̄ denotes calcite).

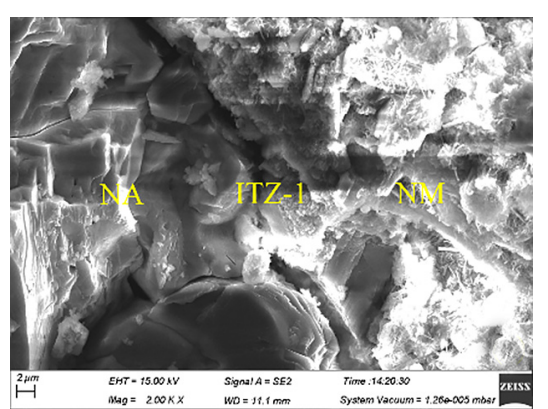

a)

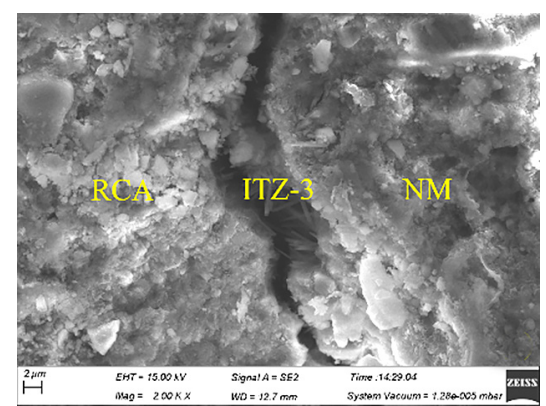

b)

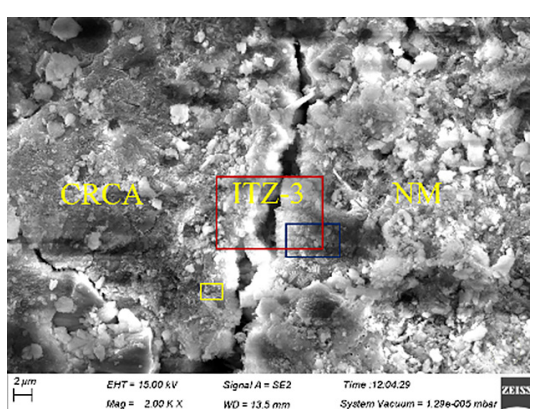

c)

Figure 16. The micro-morphology of ITZ-1 and ITZ-3 in RAC-2 and CRAC-2: a) 2 kx, ITZ-1 in RAC-2; b) 2 kx, ITZ-3 in RAC-2; c) $2 \mathrm{kx}$, ITZ-3 in CRAC-2 (CH, C-S-H, and AFt denote portlandite, calcium silicate hydrate, and ettringite, respectively). (Continue on next page) 
Wu J., Ding Y., Xu P., Zhang M., Guo M., Guo S.

of the CRCA were improved, when the apparent density increased, the water absorption and crushing value decreased.
The micro-morphology of ITZ-1 and ITZ-3 in RAC-2 and CRAC-2 is shown in Figure 16. With respect to the width of the contact boundaries between the ITZ

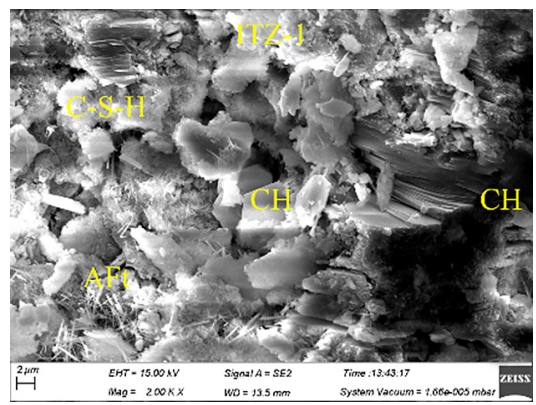

d)

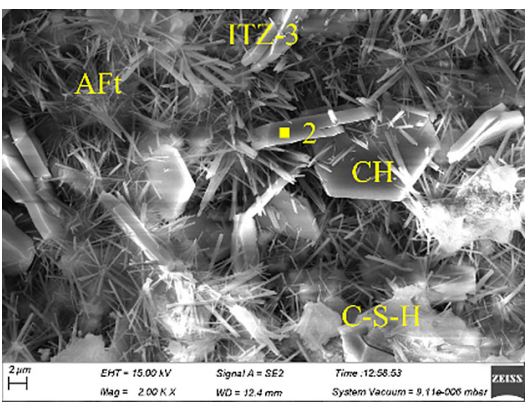

e)

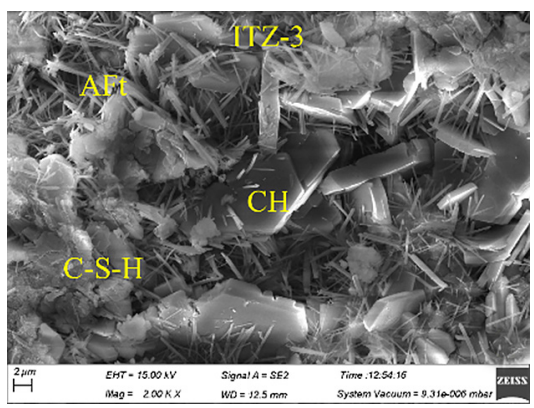

f)

Figure 16. The micro-morphology of ITZ-1 and ITZ-3 in RAC-2 and CRAC-2: d) 2 kx, ITZ-1 in RAC-2; e) 2 kx, ITZ-3 in RAC-2; f) $2 \mathrm{kx}, \mathrm{ITZ}-3$ in CRAC-2 (CH, C-S-H, and AFt denote portlandite, calcium silicate hydrate, and ettringite, respectively).

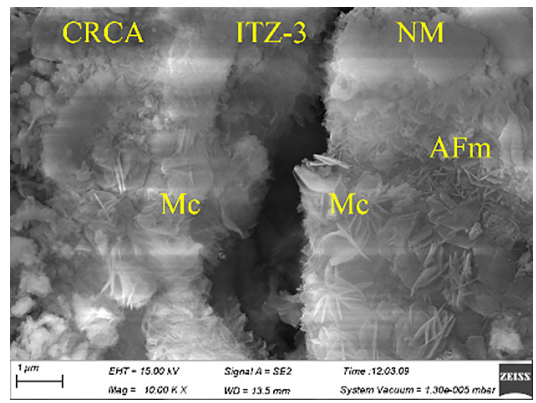

a)

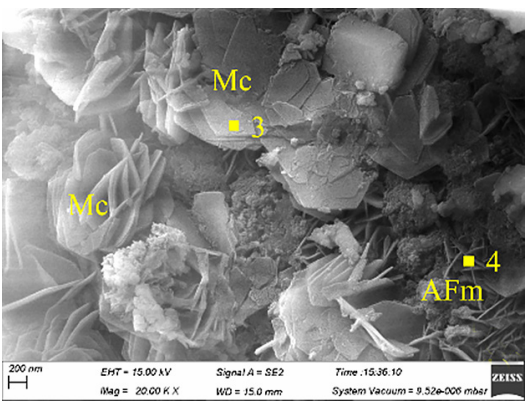

b)

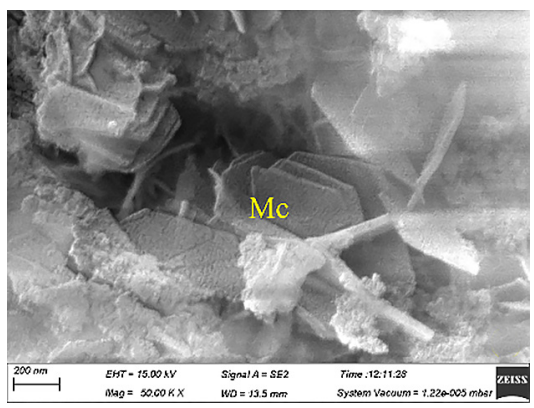

c)

Figure 17. The micro-morphology of the hydration product Mc in ITZ-3 of CRAC-2: a) $10 \mathrm{kx}$, Red rectangle in Figure $16 \mathrm{c}$; b) 20 kx, Blue rectangle in Figure 16c; c) 50 kx, Yellow rectangle in Figure 16c (Mc and AFm denote monocarbonate and monosulfate, respectively).

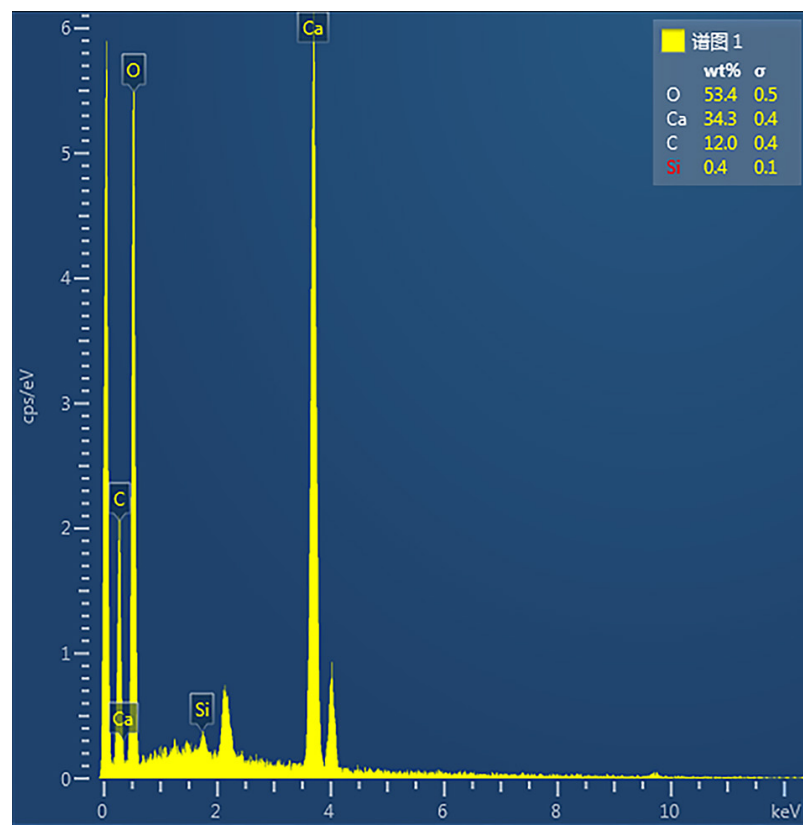

a)

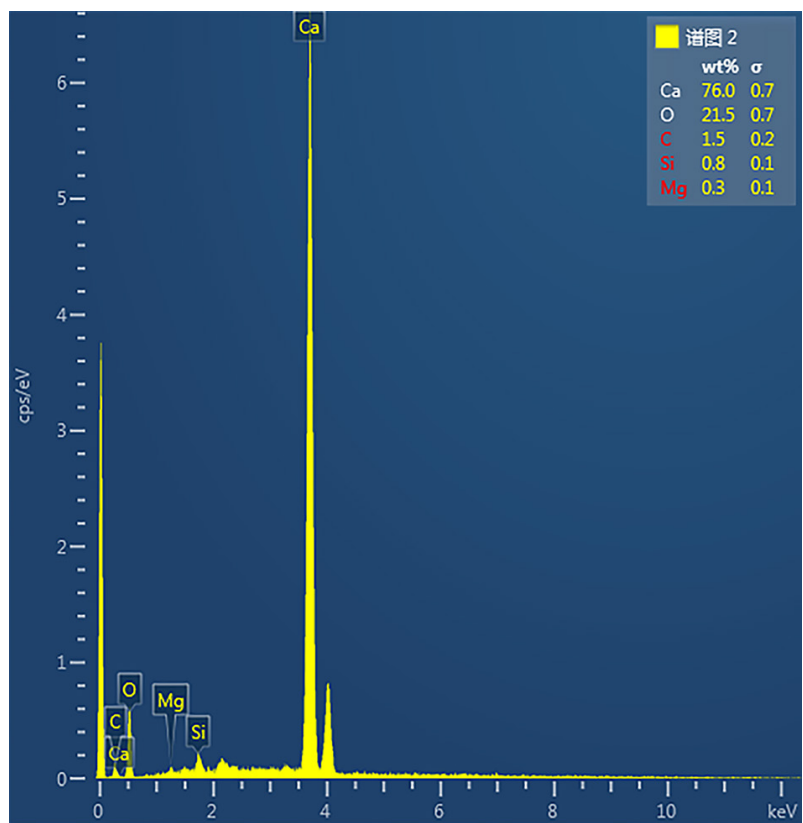

b)

Figure 18. The element analysis spectrums of the mineral crystals by EDS: a) Calcite, point 1 in Figure 15f; b) Portlandite, point 2 in Figure 16e. (Continue on next page) 


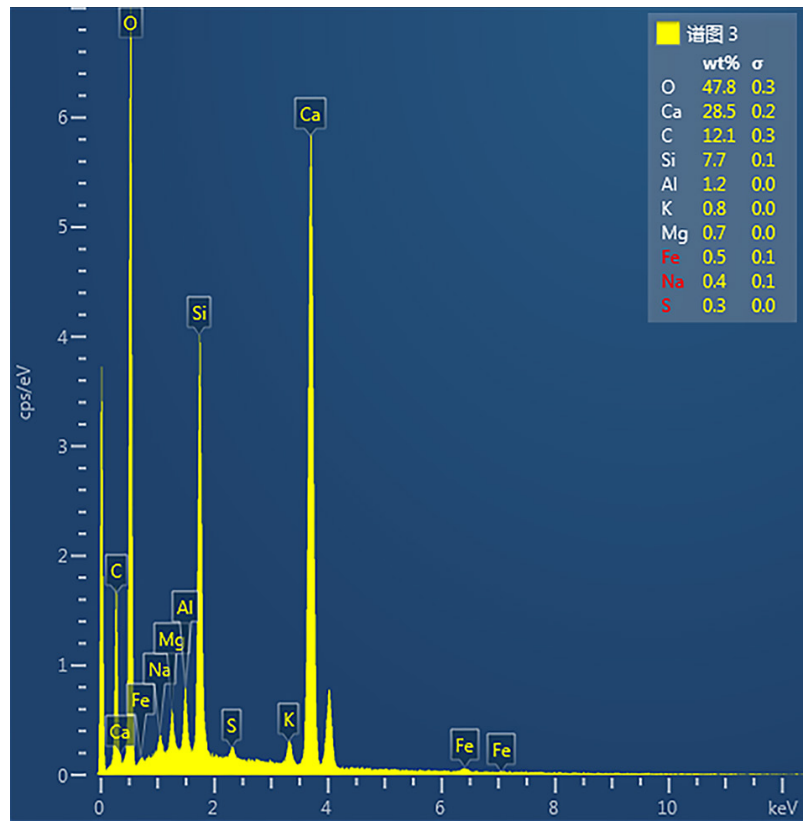

c)

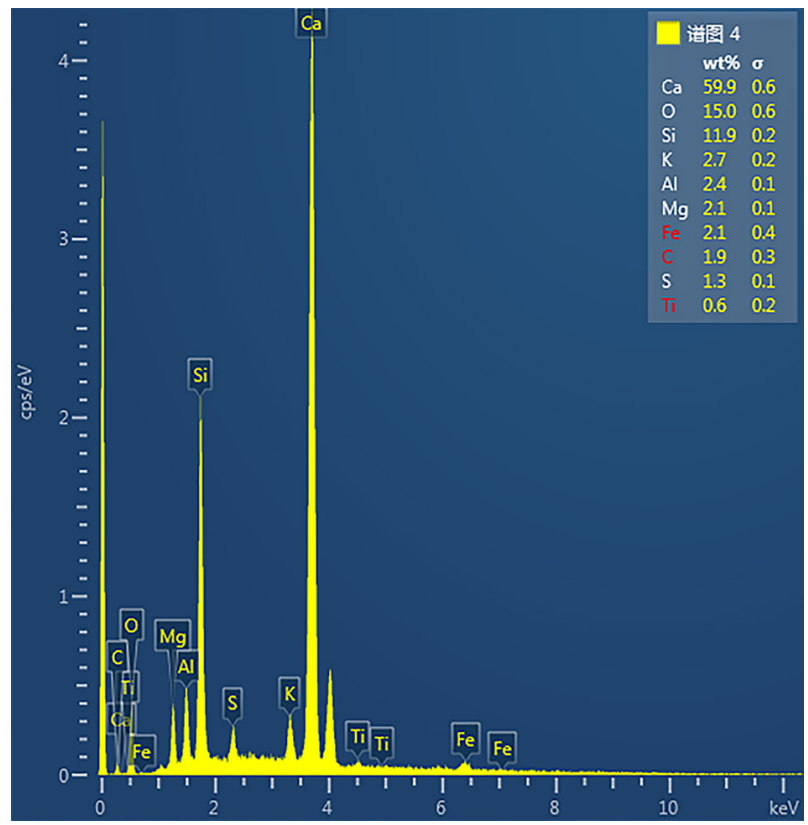

d)

Figure 18. The element analysis spectrums of the mineral crystals by EDS: c) Monocarbonate, point 3 in Figure 17b; d) Monosulfate, point 4 in Figure 17b. (Continue on next page)

and aggregate, that in Figure $16 \mathrm{~b}$ was wider than those in Figures 16a and 16c. Moreover, there was a large amount of oriented hexagonal plate portlandite $(\mathrm{CH})$ and acicular ettringite (AFt) in Figures 16e and 16f, while that in Figure 16d was less. Therefore, the properties of the ITZ-1 in RAC-2 are better than those of the ITZ-3.

The micro-morphology of the hydration product Mc in ITZ-3 of CRAC-2 is shown in Figure 17. Among which, Figures 17a,b,c correspond to the red rectangle, blue rectangle and yellow rectangle in Figure 16c, respectively. It can be seen that there was some hexagonal flake Mc in ITZ-3 of CRAC-2, which was formed by the chemical reaction between the calcite on the surface of CRCA and the aluminate in the cement paste. Besides, some petal-like AFm was also generated near Mc.

In addition, the element analysis spectrums of the mineral crystals by EDS are shown in Figure 18, combining their morphological characteristics, it can be determined that the mineral crystals at point 1 in Figure 15f, point 2 in Figure 16e, point 3 and point 4 in Figure 17b were calcite, $\mathrm{CH}, \mathrm{Mc}, \mathrm{AFm}$, respectively.

\section{$X R D$}

The XRD spectrums of the hydration products in ITZ-3 are shown in Figure 19, and Figure 20 is the enlarged view of Figure 19 in the range of $5-17^{\circ}$. It can be seen that the main minerals in specimen 1 and specimen 2 were $\mathrm{CH}$, calcite, and vaterite. The peaks of $\mathrm{CH}$ in specimen 1 were higher than that in specimen 2, while the peaks of calcite in specimen 1 were lower than that in specimen 2. It can be explained that the $\mathrm{CH}$ on the surface of the RCA reacted with $\mathrm{CO}_{2}$ to transform into calcite or vaterite after the accelerated carbonation, which is consistent with the SEM images in Figure 15. In addition, because the hydration products on the surface of the RCA reacted with $\mathrm{CO}_{2}$ in the air before pouring the cement paste, the calcite and vaterite also appeared in specimen 1 .

As shown in Figure 19, compared to specimens 1 and 2, the calcite and $\mathrm{CH}$ peaks in specimens 3 and 4 decreased, because they reacted with the aluminate in the cement paste to transform into $\mathrm{Mc}$ and $\mathrm{Hc}$, as shown in Figure 20. This result is proved by the SEM images in Figure 17.

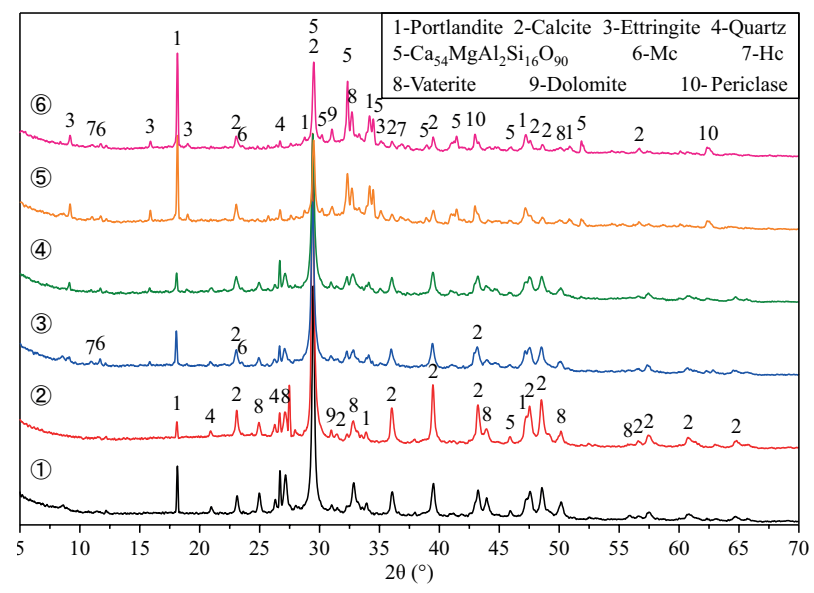

Figure 19. The XRD spectra of the hydration products in ITZ-3. 
As for specimens 5 and 6, in addition to $\mathrm{Mc}$ and $\mathrm{Hc}$, the $\mathrm{CH}$ and AFt peaks were very high in Figure 19 and Figure 20, which indicates that there is a large amount of $\mathrm{CH}$ and AFt in ITZ-3. This result is consistent with the SEM images in Figures 16e and 16f.

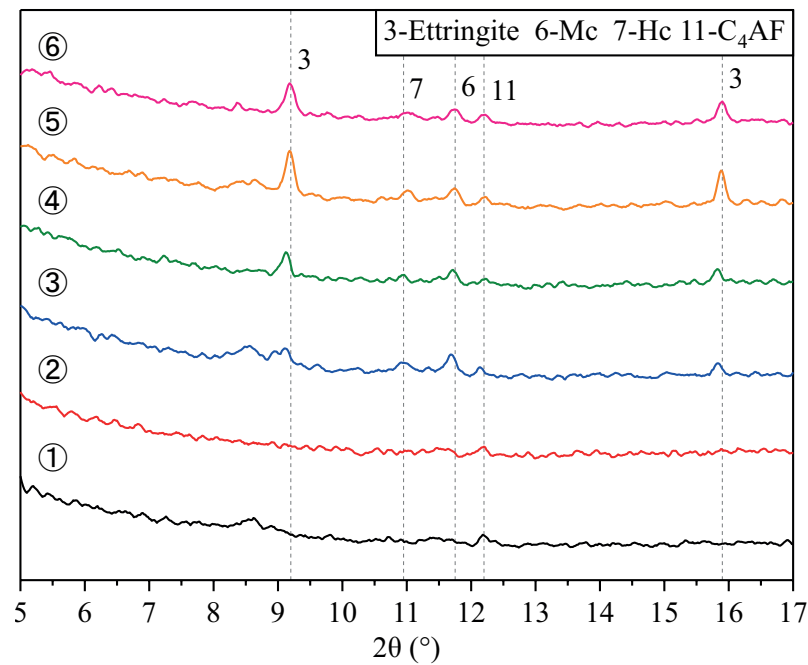

Figure 20. The XRD spectra of the hydration products in ITZ-3 (an enlarged view of Figure 19 in the range of 5-17 ).

\section{$V M H$}

The VMH of the ITZ is shown in Figure 21. It can be seen that the VMH of every phase in CRAC-2 was higher than that in RAC-2, and the change trends of the VMH of every phase in CRAC- 2 and RAC-2 were similar. The sequence of the $\mathrm{VMH}$ of every phase from low to high was ITZ-3, ITZ-1, ITZ-2, NM, OM, NA. As for CRAC-2, the VMH were 35.38, 45.98, 54.60, $57.44,62.42,218.10$, respectively. As for RAC-2, the VMH were 25.45, 35.15, 45.37, 45.84, 54.29, 218.10, respectively. Therefore, ITZ-3 was the weakest phase in CRAC-2 and RAC-2, which was consistent with the SEM images in Figure 16.

Compared to the RCA, the VMH of the ITZ-2 and $\mathrm{OM}$ in the CRCA increased by $20.34 \%$ and $14.98 \%$, respectively. Compared to RAC-2, the VMH of ITZ-3,

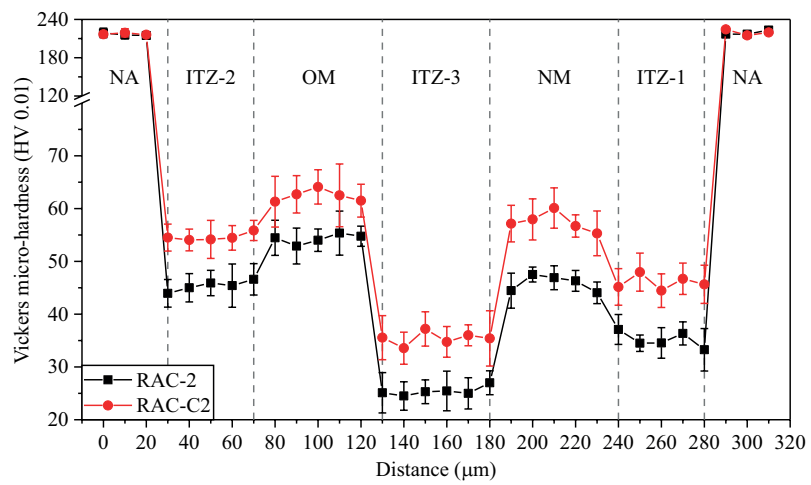

Figure 21. The VMH of the ITZ.
ITZ-1 and NM in CRAC-2 increased by $39.02 \%, 30.81 \%$, and $25.31 \%$, respectively. These results showed that the improved degree of ITZ-2 by accelerated carbonation was higher than that of OM, and the improved degrees of ITZ-3 and ITZ-1 by CRCA were higher than that of NM, which indicates that the lower their $\mathrm{VMH}$, the higher their improvement degrees.

\section{DISCUSSION}

The above-mentioned results showed that the properties of the CRCA, the mechanical properties of CRAC, and the micro-properties of ITZ-3 were improved. Their strengthening mechanisms can be explained as follows:

\section{Strengthening mechanism of the RCA} properties by accelerated carbonation

The research showed that the completely hydrated cement paste contains about $20 \% \mathrm{CH}, 70 \% \mathrm{C}-\mathrm{S}-\mathrm{H}$, $7 \%$ AFt and AFm [22]. Among which, $\mathrm{CH}$ and $\mathrm{C}-\mathrm{S}-\mathrm{H}$ are the main reactants for the accelerated carbonation, and their molar volumes increase by $12 \%$ and $23 \%$, respectively, after the accelerated carbonation, as shown in Equation 1 and Equation 2, respectively [23].

$$
\begin{aligned}
& \mathrm{Ca}(\mathrm{OH})_{2}+\mathrm{CO}_{2} \rightarrow \mathrm{CaCO}_{3}+\mathrm{H}_{2} \mathrm{O} \\
& 33 \mathrm{~cm}^{3} \cdot \mathrm{mol}^{-1} \rightarrow 37 \mathrm{~cm}^{3} \cdot \mathrm{mol}^{-1} ; \Delta \mathrm{V}=12 \% \uparrow
\end{aligned}
$$

$\mathrm{CaO} \cdot \mathrm{SiO}_{2} \cdot \mu \mathrm{H}_{2} \mathrm{O}+\mathrm{CO}_{2} \rightarrow \mathrm{CaCO}_{3}+\mathrm{SiO}_{2} \cdot \mu \mathrm{H}_{2} \mathrm{O}$ $154 \mathrm{~cm}^{3} \cdot \mathrm{mol}^{-1} \rightarrow 3 \times 37 \mathrm{~cm}^{3} \cdot \mathrm{mol}^{-1}+79 \mathrm{~cm}^{3} \cdot \mathrm{mol}^{-1}=$ $=190 \mathrm{~cm}^{3} \cdot \mathrm{mol}^{-1} ; \Delta \mathrm{V}=23 \% \uparrow$

Therefore, the strengthening mechanism of the RCA properties by accelerated carbonation can be explained by Figure 22. After the accelerated carbonation, the hydration products in the RCA and the $\mathrm{CH}$ derived from saturated lime water were transformed into the calcite, and the increase in the solid volume of the calcite exerted a filling effect on the pores and voids in the ITZ-2 and OM. The phenomena are demonstrated by the SEM images in Figure 15, and also reported by $\mathrm{Li}$ [24]. Moreover, as the $\mathrm{VMH}$ of the calcite is higher than that of the cement paste $[25,26]$, the $\mathrm{VMH}$ of the ITZ-2 and OM in the CRCA increased as shown in Figure 21, and Fang [21] also reported the same results. Finally, as shown in Table 2, the apparent density of the CRCA increased, while the water absorption and crushing value of the CRCA decreased.

\section{Strengthening mechanism of the micro-properties at ITZ-3 by CRCA}

The research showed that the ITZ is composed of three phases, including a water film, a layer of $\mathrm{CH}$ and AFt crystals, and a layer porous $\mathrm{C}-\mathrm{S}-\mathrm{H}$ [11], and it is the weakest phase in the RAC, which plays a crucial role in 
affecting the mechanical properties and durability of the RAC [12,13]. Generally, the formation and properties of ITZ are affected by the wall effect of aggregate and micro-bleeding effect of the ITZ, as well as the mineral composition and micro-structure of the aggregate surface. After the accelerated carbonation, the mineral composition and micro-structure of the RCA surface changed, which affects the formation and properties of the ITZ-3.

As shown in Figure 23, the strengthening mechanism of the micro-properties at ITZ-3 by CRCA can be explained by the nucleation effect and chemical effect of the calcite and the micro-bleeding effect of the ITZ-3. The research showed that the main mineral composition of the RCA surface is $\mathrm{C}-\mathrm{S}-\mathrm{H}$, which relies on a relatively weak electrostatic interaction to adsorb $\mathrm{Ca}^{2+}$. Therefore, little $\mathrm{Ca}^{2+}$ can be adsorbed on the surface of the RCA, which makes it difficult for $\mathrm{C}-\mathrm{S}-\mathrm{H}$ to nucleate and grow on the surface of the RCA. By contrast, the surface of the CRCA is covered by a large amount of calcite, which relies on a relatively strong acid-base interaction to adsorb $\mathrm{Ca}^{2+}$ $[27,28]$. Consequently, the calcite exerted a nucleation effect. Specifically, calcite provided sites for $\mathrm{C}-\mathrm{S}-\mathrm{H}$ to nucleate and grow [29,30], thus forming a dense RCA surface. On the other hand, as shown in Equation 3 and Equation 4 [31], the calcite exerted a chemical effect that it reacted with the aluminate in ITZ-3 to form Hc and Mc [32]. This phenomenon is proved by the SEM images in Figure 17 and the XRD spectrums in Figure 20 , and it is consistent with the results reported by Zhan [18]. Moreover, with an increase in the hydration age, Hc gradually transforms into Mc [33], and meanwhile it inhibits the transformation of AFt to AFm, which benefits the stability of AFt and an increase in the solid volume of the cement paste $[14,25,34]$. In addition, a decrease in the water absorption of the CRCA alleviated the microbleeding effect of ITZ-3. Eventually, the synergistic effect of these three factors slightly reduced the porosity of ITZ-3 and increased the VMH of ITZ-3 as shown in Figure 21.
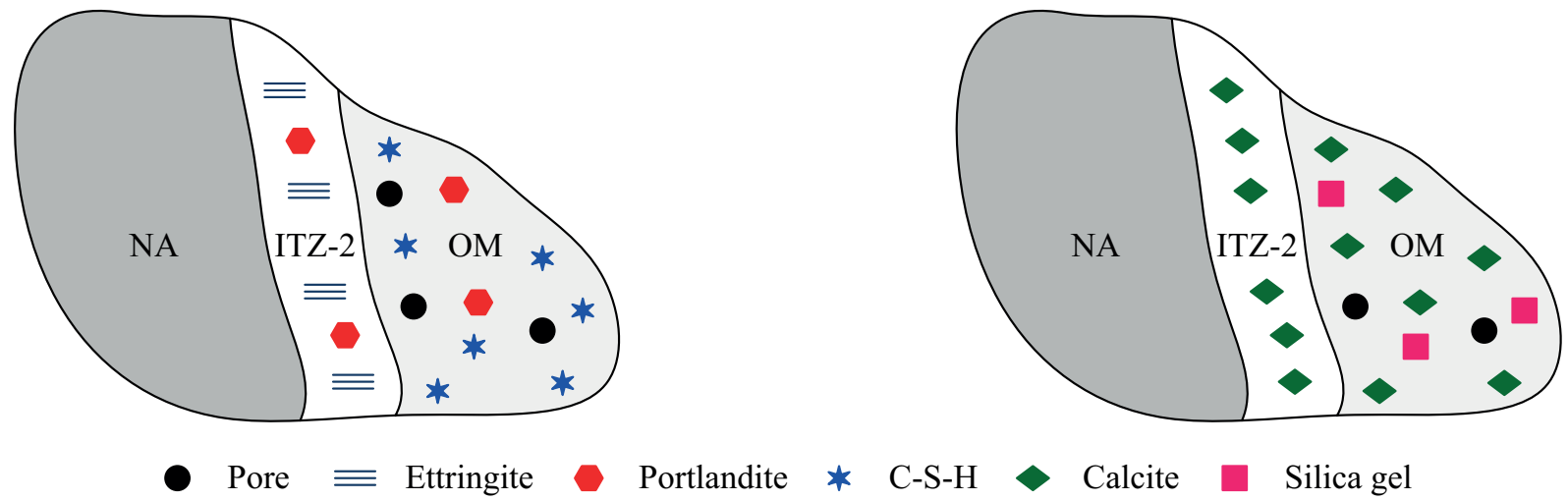

$\mathrm{RCA} \stackrel{\text { Accelerated carbonation }}{\longrightarrow} \mathrm{CRCA}$

Figure 22. The strengthening mechanism of the RCA properties by accelerated carbonation.
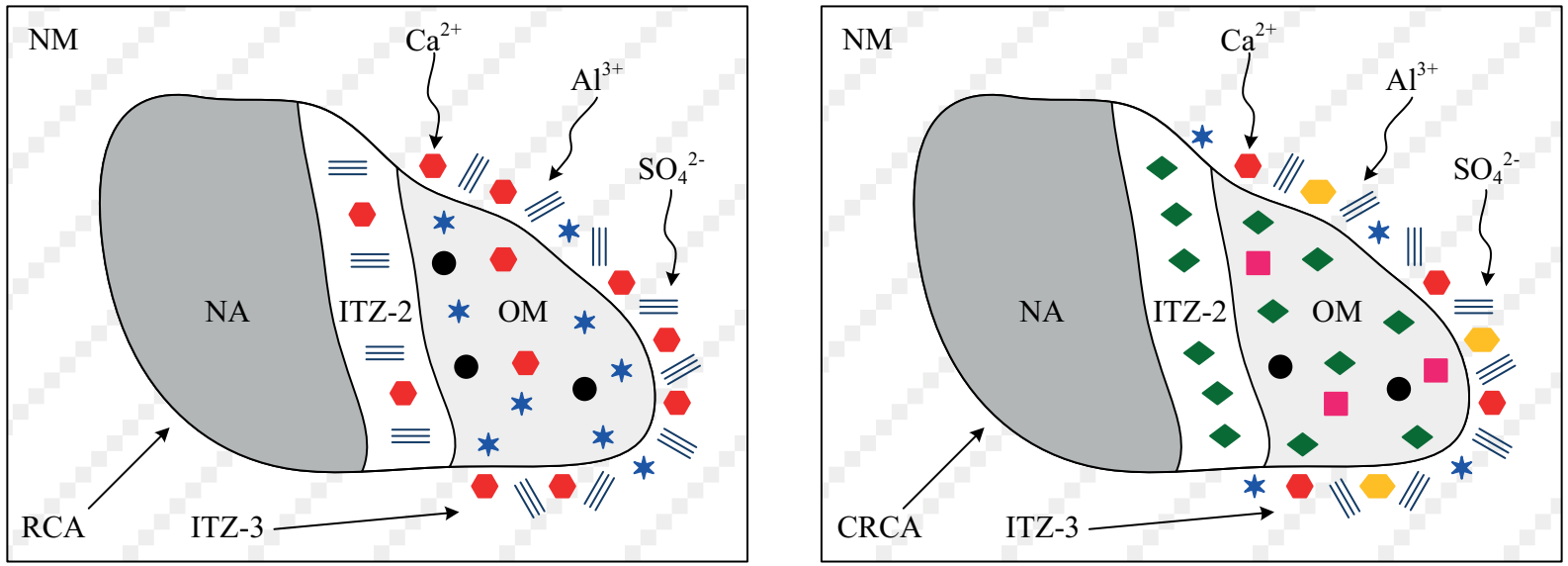

Pore $\equiv$ Ettringite

Portlandite * C-S-H

Calcite

Silica gel

Monocarbonate

RAC prepared by RCA

RAC prepared by CRCA

Figure 23. The strengthening mechanism of the micro-properties at ITZ-3 by CRCA. 
$3 \mathrm{CaO} \cdot \mathrm{Al}_{2} \mathrm{O}_{3}+\mathrm{CaCO}_{3}+11 \mathrm{H}_{2} \mathrm{O} \rightarrow$

$\rightarrow 3 \mathrm{CaO} \cdot \mathrm{Al}_{2} \mathrm{O}_{3} \cdot \mathrm{CaCO}_{3} \cdot 11 \mathrm{H}_{2} \mathrm{O}$

$89 \mathrm{~cm}^{3} \cdot \mathrm{mol}^{-1}+37 \mathrm{~cm}^{3} \cdot \mathrm{mol}^{-1} \rightarrow$

$\rightarrow 262 \mathrm{~cm}^{3} \cdot \mathrm{mol}^{-1} ; \Delta \mathrm{V}=108 \% \uparrow$

$3 \mathrm{CaO} \cdot \mathrm{Al}_{2} \mathrm{O}_{3}+0.5 \mathrm{CaCO}_{3}+0.5 \mathrm{Ca}(\mathrm{OH})_{2}+11.5 \mathrm{H}_{2} \mathrm{O} \rightarrow$

$3 \mathrm{CaO} \cdot \mathrm{Al}_{2} \mathrm{O}_{3} \cdot 0.5 \mathrm{CaCO}_{3} \cdot 0.5 \mathrm{Ca}(\mathrm{OH})_{2} \cdot 11.5 \mathrm{H}_{2} \mathrm{O}$

$89 \mathrm{~cm}^{3} \cdot \mathrm{mol}^{-1}+0.5 \times 37 \mathrm{~cm}^{3} \cdot \mathrm{mol}^{-1}+0.5 \times 33 \mathrm{~cm}^{3} \cdot \mathrm{mol}^{-1} \rightarrow$

$\rightarrow 285 \mathrm{~cm}^{3} \cdot \mathrm{mol}^{-1} ; \Delta \mathrm{V}=130 \% \uparrow$

\section{Strengthening mechanism of the mechanical properties of the RAC by CRCA}

The research showed that the mechanical properties of the RAC are controlled by the ITZ, which is the weakest phase in the RAC. As shown in Table 2, the water absorption of the RCA is about $5-10$ times than that of NA, which leads to ITZ-3 being inferior to ITZ-1 because of the micro-bleeding effect of the ITZ. As a result, the mechanical properties of the RAC are controlled by ITZ-2 and ITZ-3. Besides, when the waterbinder ratio of the RAC is low, the properties of ITZ-3 are superior to those of ITZ-2. When the water-binder ratio of the RAC is high, the properties of ITZ-3 are inferior to those of ITZ-2 [35]. In this study, as shown in Figure 21, ITZ-3 had the lowest VMH. Therefore, the mechanical properties of the RAC were governed by ITZ-3.

In conclusion, the strengthening mechanism of the mechanical properties of the RAC by CRCA can be explained from three aspects. Firstly, after the accelerated carbonation, the properties of the OM and ITZ-2 in the CRCA were improved. Secondly, the properties of ITZ-3 were improved by the nucleation effect and chemical effect of the calcite and the micro-bleeding effect of ITZ-3. Thirdly, as a saturated surface dry state aggregate was used in this study, a decrease in the water absorption of the CRCA led to a lower water-binder ratio in the RAC, which improved the properties of ITZ-1 and NM. Eventually, the mechanical properties of the RAC were improved by the CRCA.

\section{CONCLUSIONS}

In this paper, the effects of the CRCA on the mechanical properties of the RAC and the micro-properties of the ITZ were studied, and their strengthening mechanisms were explained. The main conclusions can be drawn as follows:

- The pores of the OM and ITZ-2 in the CRCA were filled with calcite formed during the accelerated carbonation process, thus the properties of the CRCA were improved, with an increased apparent density, a decreased water absorption and crushing value.

- The mechanical properties of the RAC at the ages of 7 days and 28 days gradually decreased with the replacement ratio of the RCA. By contrast, the mechanical properties of the CRAC at the ages of 7 days and 28 days improved compared to those of the RAC, and the improvement degree increased with the replacement ratio of the CRCA. Moreover, the relationships between the mechanical properties of the RAC were consistent with those of the NAC.

- Compared to other RAC phases, such as ITZ-1, ITZ-2, NM and OM, ITZ-3 had the lowest VMH values, but had the highest degree of improvement. This finding indicates that the lower the properties of the ITZ, the higher the degrees of improvement by the accelerated carbonation and CRCA.

- The strengthening mechanism of the micro-properties at ITZ-3 by CRCA can be explained by the nucleation effect and chemical effect of the calcite and the microbleeding effect of ITZ-3. Namely, the calcite on the surface of CRCA provided nucleation sites for $\mathrm{C}-\mathrm{S}-\mathrm{H}$ and also reacted with the aluminate in ITZ-3 to form $\mathrm{Hc}$ and Mc. In addition, the decrease in the water absorption of the CRCA alleviated the micro-bleeding effect of ITZ-3.

\section{Acknowledgments}

This work was supported by the Joint Funds of the National Natural Science Foundation of China (Grant No. U1904188), and the Key Science and Technology Program of Henan Province, China (Grant No. 202102310253).

\section{REFERENCES}

1. Akhtar A., Sarmah A.K. (2018): Construction and demolition waste generation and properties of recycled aggregate concrete: A global perspective. Journal of Cleaner Production, 186, 262-281. Doi: 10.1016/j.jclepro.2018.03.085

2. Tam V.W.Y., Soomro M., Evangelista A.C.J. (2018): A review of recycled aggregate in concrete applications (2000-2017). Construction and Building Materials, 172, 272-292. Doi: 10.1016/j.conbuildmat.2018.03.240

3. Tam V.W.Y., Wattage H., Le K.N., Buteraa A., Soomro M. (2021): Methods to improve microstructural properties of recycled concrete aggregate: A critical review. Construction and Building Materials, 270, 121490. Doi: 10.1016/j.conbuildmat.2020.121490

4. Mistri A., Bhattacharyya S.K., Dhami N., Mukherjee A., Barai S.V. (2020): A review on different treatment methods for enhancing the properties of recycled aggregates for sustainable construction materials. Construction and Building Materials, 233, 117894. Doi: 10.1016/j.conbuildmat.2019.117894

5. Zhang H.R., Zhao Y.X. (2015): Integrated interface parameters of recycled aggregate concrete. Construction and Building Materials, 101, 861-877. Doi: 10.1016/j.conbuildmat.2015. 10.084

6. Xiao J.Z., Li W.G., Fan Y.H., Huang X. (2012): An overview of study on recycled aggregate concrete in China (1996-2011). Construction and Building Materials, 31, 364-383. Doi: 10. 1016/j.conbuildmat.2011.12.074

7. Kisku N., Joshi H., Ansari M., Panda S.K., Nayak S., Dutta S.C. (2017): A critical review and assessment for usage of recycled aggregate as sustainable construction material. 
Construction and Building Materials, 131, 721-740. Doi: 10 1016/j.conbuildmat.2016.11.029

8. Guo H., Shi C.J., Guan X.M., Zhu J.P., Ding Y.H., Ling T.C., Zhang H.B., Wang Y.L. (2018): Durability of recycled aggregate concrete - A review. Cement and Concrete Composites, 89, 251-259. Doi: 10.1016/j.cemconcomp.2018.03. 008

9. Katkhuda H., Shatarat N. (2017): Improving the mechanical properties of recycled concrete aggregate using chopped basalt fibers and acid treatment. Construction and Building Materials, 140, 328-335. Doi: 10.1016/j.conbuildmat.2017. 02.128

10. Ren X., Zhang L.Y. (2018): Experimental study of interfacial transition zones between geopolymer binder and recycled aggregate. Construction and Building Materials, 167, 749-756. Doi: 10.1016/j.conbuildmat.2018.02.111

11. Djerbi A. (2018): Effect of recycled coarse aggregate on the new interfacial transition zone concrete. Construction and Building Materials, 190, 1023-1033. Doi: 10.1016/j.conbuildmat 2018.09.180

12. Wang R.J., Yu N.N., Li Y. (2020): Methods for improving the microstructure of recycled concrete aggregate: A review. Construction and Building Materials, 242, 118164. Doi: 10.1016/j.conbuildmat.2020.118164

13. Yue Y.C., Zhou Y.W., Xing F., Gong G.Q., Hu B., Guo M.H. (2020): An industrial applicable method to improve the properties of recycled aggregate concrete by incorporating nanosilica and micro-CaCO ${ }_{3}$. Journal of Cleaner Production, 259 , 120920. Doi: 10.1016/j.jclepro.2020.120920

14. Liang C.F., Pan B.H., Ma Z.M., He Z.H., Duan Z.H. (2020): Utilization of $\mathrm{CO}_{2}$ curing to enhance the properties of recycled aggregate and prepared concrete: A review. Cement and Concrete Composites, 105, 103446. Doi: 10.1016/j.cemconcomp.2019.103446

15. Kou S.C., Zhan B.J., Poon C.S. (2014): Use of a $\mathrm{CO}_{2}$ curing step to improve the properties of concrete prepared with recycled aggregates. Cement and Concrete Composites, 45, 22-28. Doi: 10.1016/j.cemconcomp.2013.09.008

16. Xuan D.X., Zhan B.J., Poon C.S. (2016): Assessment of mechanical properties of concrete incorporating carbonated recycled concrete aggregates. Cement and Concrete Composites, 65, 67-74. Doi: 10.1016/j.cemconcomp.2015.10.018

17. Li L., Xiao J.Z., Xuan D.X., Poon C.S. (2018): Effect of carbonation of modeled recycled coarse aggregate on the mechanical properties of modeled recycled aggregate concrete. Cement and Concrete Composites, 89, 169-180. Doi: 10.1016/j.cemconcomp.2018.02.018

18. Zhan B.J., Xuan D.X., Poon C.S., Scrivener K.L. (2020): Characterization of interfacial transition zone in concrete prepared with carbonated modeled recycled concrete aggregates. Cement and Concrete Research, 136, 106175. Doi: 10.1016/j.cemconres.2020.106175

19. Pan G.H., Zhan M.M., Fu M.H., Wang Y.P., Lu X.J. (2017): Effect of $\mathrm{CO}_{2}$ curing on demolition recycled fine aggregates enhanced by calcium hydroxide pre-soaking. Construction and Building Materials, 154, 810-818. Doi: 10.1016/j.conbuildmat.2017.07.079

20. Zhan B.J., Xuan D.X., Poon C.S. (2018): Enhancement of recycled aggregate properties by accelerated $\mathrm{CO}_{2}$ curing coupled with limewater soaking process. Cement and Concrete Composites, 89, 230-237. Doi: 10.1016/j.cemconcomp.2018. 03.011

21. Fang X.L., Zhan B.J., Poon C.S. (2021): Enhancement of recycled aggregates and concrete by combined treatment of spraying $\mathrm{Ca}^{2+}$ rich wastewater and flow-through carbonation. Construction and Building Materials, 277, 122202. Doi: 10.1016/j.conbuildmat.2020.122202
22. Zhang J.K., Shi C.J., Li Y.K., Pan X.Y., Poon C.S., Xie Z.B. (2015): Performance enhancement of recycled concrete aggregates through carbonation. Journal of Materials in Civil Engineering, 27 (11), 04015029. Doi: 10.1061/(ASCE) MT.1943-5533.0001296

23. Luo S.R., Ye S.C., Xiao J.Z., Zheng J.L., Zhu Y.T. (2018): Carbonated recycled coarse aggregate and uniaxial compressive stress-strain relation of recycled aggregate concrete. Construction and Building Materials, 188, 956-965. Doi: 10.1016/j.conbuildmat.2018.08.159

24. Li Y., Fu T.H., Wang R.J., Li Y. (2020): An assessment of microcracks in the interfacial transition zone of recycled concrete aggregates cured by $\mathrm{CO}_{2}$. Construction and Building Materials, 236, 117543. Doi: 10.1016/j.conbuildmat.2019. 117543

25. Liu B.J., Qin J.L., Shi J.Y., Jiang J.Y., Wu X., He Z.H. (2021): New perspectives on utilization of $\mathrm{CO}_{2}$ sequestration technologies in cement-based materials. Construction and Building Materials, 272, 121660. Doi: 10.1016/j.conbuildmat. 2020.121660

26. Pu Y.H., Li L., Wang Q.Y., Shi X.S., Luan C.C., Zhang G.M., Fu L., El-Fatah Abomohra A. (2021): Accelerated carbonation technology for enhanced treatment of recycled concrete aggregates: A state-of-the-art review. Construction and Building Materials, 282, 122671. Doi: 10.1016/j. conbuildmat.2021.122671

27. Ouyang X.W., Wang L.Q., Xu S.D., Ma Y.W., Ye G. (2020): Surface characterization of carbonated recycled concrete fines and its effect on the rheology, hydration and strength development of cement paste. Cement and Concrete Composites, 114, 103809. Doi: 10.1016/j.cemconcomp.2020.103809

28. Ouyang X.W., Koleva D.A., Ye G., van Breugel K. (2017): Insights into the mechanisms of nucleation and growth of $\mathrm{C}-\mathrm{S}-\mathrm{H}$ on fillers. Materials and Structures, 50 (5), 213. Doi: 10.1617/s11527-017-1082-y

29. Lothenbach B., Le Saout G., Gallucci E., Scrivener K. (2008): Influence of limestone on the hydration of Portland cements. Cement and Concrete Research, 38 (6), 848-860. Doi: 10.1016/j.cemconres.2008.01.002

30. Kakali G., Tsivilis S., Aggeli E., Bati M. (2000): Hydration products of $\mathrm{C}_{3} \mathrm{~A}, \mathrm{C}_{3} \mathrm{~S}$ and Portland cement in the presence of $\mathrm{CaCO}_{3}$. Cement and Concrete Research, 30 (7), 1073-1077. Doi: 10.1016/S0008-8846(00)00292-1

31. De Weerdt K., Haha M.B., Le Saout G., Kjellsen K.O., Justnes H., Lothenbach B. (2011): Hydration mechanisms of ternary Portland cements containing limestone powder and fly ash. Cement and Concrete Research, 41 (3), 279-291. Doi: 10.1016/j.cemconres.2010.11.014

32. Liu S.H., Shen P.L., Xuan D.X., Li L., Sojobi A., Zhan B.J., Poon C.S. (2021): A comparison of liquid-solid and gassolid accelerated carbonation for enhancement of recycled concrete aggregate. Cement and Concrete Composites, 118, 103988. Doi: 10.1016/j.cemconcomp.2021.103988

33. Zajac M., Rossberg A., Le Saout G., Lothenbach B. (2014): Influence of limestone and anhydrite on the hydration of Portland cements. Cement and Concrete Composites, 46, 99-108. Doi: 10.1016/j.cemconcomp.2013.11.007

34. Bonavetti V.L., Rahhal V.F., Irassar E.F. (2001): Studies on the carboaluminate formation in limestone filler-blended cements. Cement and Concrete Research, 31 (6), 853-859. Doi: 10.1016/S0008-8846(01)00491-4

35. Otsuki N., Miyazato S., Yodsudjai W. (2003): Influence of recycled aggregate on interfacial transition zone, strength, chloride penetration and carbonation of concrete. Journal of Materials in Civil Engineering, 15 (5), 443-451. Doi: 10.1061/(ASCE)0899-1561(2003)15:5(443) 